Alma Mater Studiorum - Università di Bologna DEPARTMENT OF ECONOMICS

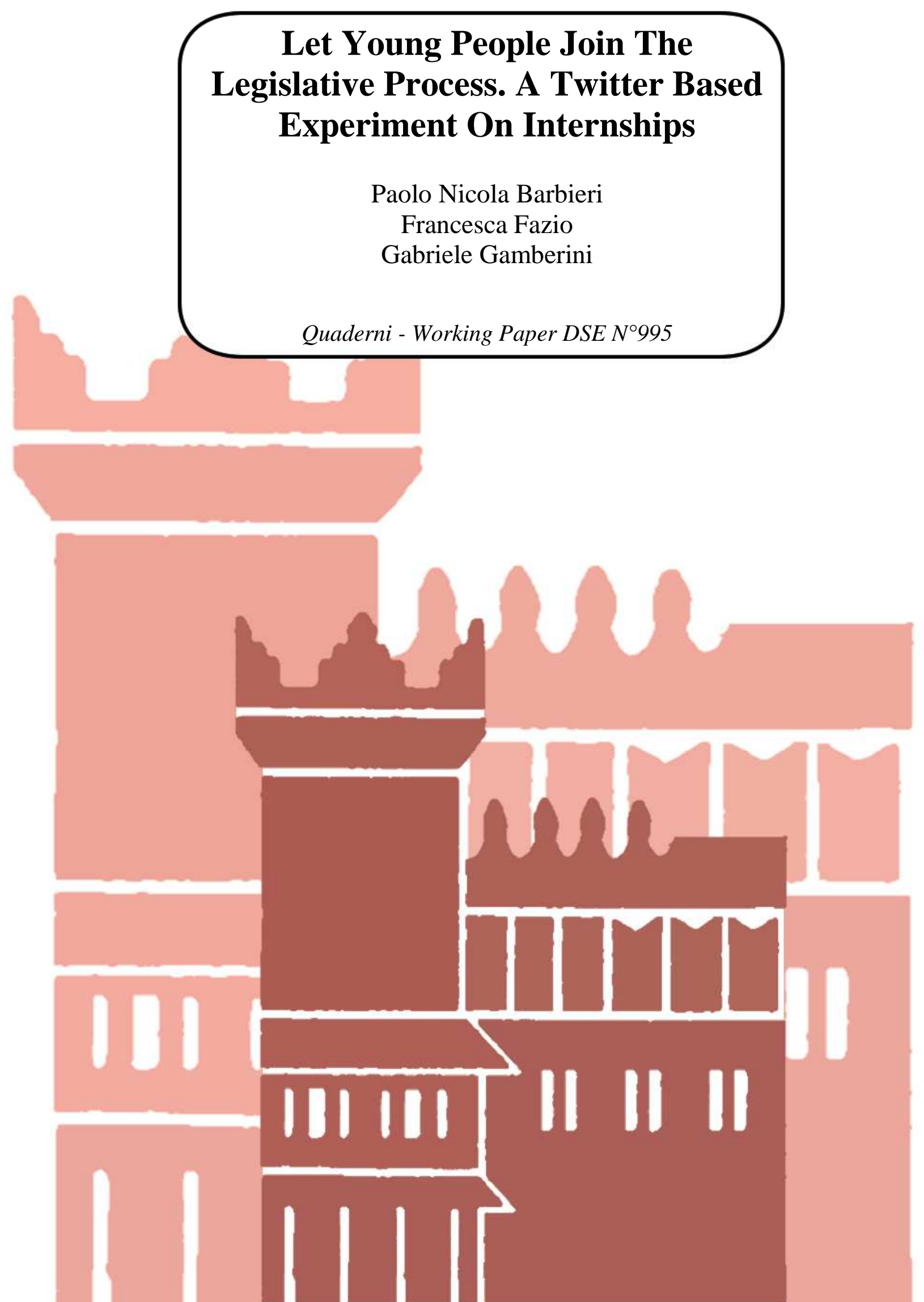




\title{
Let Young People Join The Legislative Process. A Twitter Based Experiment On Internships
}

\author{
Paolo Nicola Barbieri*† Francesca Fazio ${ }^{\ddagger}$ Gabriele Gamberini ${ }^{\S}$
}

August 2, 2014

\begin{abstract}
The aim of this research is to examine the possible effects of labour market institutional characteristics on young people's perceptions of their internship experiences as expressed on Twitter. By looking at these opinions (satisfaction versus dissatisfaction) in relation to certain features of internships as well as to the more general labour market regulatory framework, this project aims to give a voice to young people, enabling them (indirectly) to provide policy suggestions to law-makers. Furthermore, we propose a preview of a possible empirical model for data collection based on the manual coding of Tweets. By employing a Probit regression and Blinder-Oaxaca and Fairlie decompositions, we have tried to establish a link between the perceived evaluation of internships and the country where the internship is based, the latter being used as a proxy for the legal system. In all our tests we found that the country in which the internship is placed is the main factor in the positive or negative perception. Ultimately we shall propose the use of Twitter not only as a relevant research tool, but also as an instrument for bringing young people's needs to the attention of law-makers.
\end{abstract}

JEL-Classification: J28, K31, Z13

Keywords: youth employment; internships; labour market institutions; employment protection legislation; Twitter

\footnotetext{
${ }^{*}$ We are grateful to Giovanni Fiorillo, Edoardo Morselli and Jessica Nespoli for the data collecting work. This paper draws on research presented on August 2nd 2014 at the London School of Economics conference "Social Justice 2014: the institutions that make social justice" in panel No. 13 on "Full employment and training".

${ }^{\dagger}$ Corresponding author. University of Bologna, Department of Economics, P.zza Scaravilli 2, 40126 - Bologna (Italy) E-mail address: paolonicola.barbieri@unibo.it

${ }^{\ddagger}$ University of Modena and Reggio Emilia, "Marco Biagi" Department of Economics, DEAL Centre for International and Comparative Studies, Viale Jacopo Berengario, 5141121 Modena (MO) - Italy.

§University of Modena and Reggio Emilia, "Marco Biagi" Department of Economics, DEAL Centre for International and Comparative Studies, Viale Jacopo Berengario, 5141121 Modena (MO) - Italy.
} 


\section{Introduction}

Studying comparative legal systems in the framework of academic law research is a rather conservative exercise. In fact, legal systems can be explained through the 'Autopoiesis' theory posited by Maturana and Varela (Maturana and Varela, 1987), subsequently applied to society's sub-systems, including legal systems, by Luhmann (Luhmann, 1988). According to this parallelism, legal systems maintain their autonomy and reproduce themselves in a self-referential way, i.e. using their own elements only.

Legal systems are characterised by a "cognitive openness" (Baxter, 1997), which allows them to detect external inputs, but also by an "operational closure" (Luhmann, 1991), which impedes the reception of these external inputs because the information comes in a different language.

There is no exchange of information between different systems, but rather structural coupling (Luhmann, 1991) by means of which different systems can translate external influences into their own language and thus co-evolve, nonetheless maintaining their structure and autonomy.

This can happen through the existence of common elements in different systems known as gateways which have meaning in each system's code. Gateways are necessary in order to allow communication and co-evolution between systems as inputs coming from one system, if conveniently translated, can be received by another.

Translation is necessary because each system needs internal coherence in order to survive and selfreproduce (Carvalho and Deakin, 2011). For example, every new elaboration by each legal sub-system (norms, jurisprudence) is built upon the perpetuation of existing traditional and generally shared models. Naturally, impulses coming from external systems may have effects on the legal system, but it is not clear which system exerts the strongest influence. Mapping inputs coming into the legal system from other systems is impossible due to the huge quantity of existing systems and sub-systems. Since it is not possible to accurately measure who is able to influence the legal system it can be argued that laws and judgments may be mostly influenced by groups expressing the interests of powerful minorities. Indeed, weaker groups (due to the asymmetry of information, their vulnerable position in society, lack of representation and so on), may find it difficult to interact and communicate with the legal system.

The scarce inclusion of vulnerable people - including young people - in the decision-making process may pose a problem in terms of social justice as laws, and consequentially judgments, may not answer to general interests, but to those of the more influential groups. In this sense, social justice could be achieved when parties interact through an 'I-Thou' relationship, i.e. when everyone acknowledges and treats everyone else as an autonomous, authentic subject (Buber, 1937)

A legal system which seems particularly exposed to an issue of social justice is the labour market. Indeed, labour market history can be seen as a struggle for the transition from the 'I-It' relationship to the 'I-Thou' relationship Grantham and MacKinnon, 1994.

For many years the labour market has been working as an 'I-It' relationship, with employers treating

\footnotetext{
${ }^{1}$ The opposite is the "I-It" relation, when everyone treats everyone else as an object to be used.
} 
employees as commodities, but today, at least in developed countries, employment relations can be represented mostly as an 'I-Thou' relationship, thanks to, among other things, the increasing protection of workers provided by laws which, to a certain extent, has been directly influenced by workers by means of strikes and protests.

Although employment conditions today may be improved, emerging trends in the labour market pose new challenges and issues in terms of social justice.

A particularly critical condition is that of interns, who work without an employment contract and who, in general, are not entitled to sufficient levels of employment protection (Edwards and Hertel-Fernandez, 2010) The abuse associated with this instrument often entails increasing precariousness, thus representing a possible limitation of young people's ability to fully realise their potential in the society they live in (Burke and Carton, 2013). Being a quite recent phenomenon, the exploitation of interns has rarely been addressed by national law-makers (Hadjivassiliou et al., 2012). However, it can be argued that, as in the case of employees, interns will reach a certain level of protection only after protests and rallies 3 . In order to prevent and avoid these drastic, and potentially dangerous, events, it is necessary to find another way to address impulses coming from young people to the legal system in order to achieve social justice by means of an 'I-Thou' relationship also in this area of the labour market.

Institutions, especially at the EU level, could play a pivotal role in increasing the level of social justice and preventing youth exploitation. Indeed, the EU has started a process of negotiations and consultations to agree on a European Quality Framework for Traineeship\$4. In spite of its importance, this soft law intervention might not be sufficient to guarantee decent work for young interns, leaving them under-protected due to an unbalanced relationship with employers (Hall et al. 1995)

The aim of this research project is to create a model for a fair and bottom-up dialogue between interns and law-makers in order to build a legal system based on an 'I-Thou' relationship, in which interns can obtain representation and protection which can be translated into laws and policies by law-makers inspired by a sense of social justice, as well as political interests.

In this respect, this paper will analyse possible relationships between young people's perceptions of internships on the one hand, and on the other institutional characteristics of the labour market (employment protection legislation and other dimensions specifically concerning internships, i.e. degree of protection, pay

\footnotetext{
${ }^{2}$ The authors assert that "a lack of clear regulation and enforcement of internship-related laws: (1) leaves many interns unprotected by workplace discrimination and harassment statues [...]; (2) fosters the growth of unpaid internships, which in turn limits participation to only the students who can afford to forego wages and pay for living expenses, effectively institutionalizing socioeconomic disparities; and (3) permits (and even incentivizes) the replacement of regular workers with unpaid college students and recent graduates".

${ }^{3}$ Nowadays interns are starting to organise protests in order to achieve protection of their rights. As example see the so-called 'Sandwich Protest' against unfair internship conditions which took place in Brussels (Belgium) on July 17th, 2013.

${ }^{4}$ See Council of European Union, Recommendation on a Quality Framework for Traineeships, March 10th 2014, No. 2014/C 88/01, available at http://eur-lex.europa.eu/legal-content/EN/TXT/PDF/?uri=CELEX:32014H0327 (01)\&qid= $1406148805692 \&$ from=EN

"The authors, as the conclusion of their survey, assert that "disparities in internship expectations [between intern and employer] probably exist in most programs" and "the best example of this is found in the question of a permanent job offer at the end of the internship - the students expect it and the employers do not".
} 
dispositions, working conditions, rights and obligations, employment status (Bird, 2012, Coker, 2009, Keiser et al. 2013, Lavin, 2013, Nelson, 2010 in seven European countries and in the United States?

In addition to this aim, we propose a novel model for data collection based on Twitter.

As an experiment we collected over 500 Tweets written by European and non-European young people directly experiencing an internship, categorising them in order to obtain an illustrative data sample suitable for econometric analysis. Then, employing multiple regression analysi 8 , we looked for a possible causal link between the perceived evaluation of internships, the countries where they took place and their legal systems.

The remainder of this paper is organised as follows. The next section provides a literature review of Twitter and social sciences. In the subsequent section, the theoretical background of our research will be explained. The methodology and results of our study will then be presented and in conclusion our results, research and their practical implications will be discussed, as well as limitations and potential future work.

\section{Twitter as a Model for Empirical Research Analysis}

The internet and social media are strikingly increasing the amount of information about and interaction between individuals, unveiling their expressions and ideas and thus representing for social scientists a unique and unexplored source from which to analyse, measure and understand previously hidden social mechanisms. Among social media, Twitter, with more than 255 million users worldwide and over 500 million Tweets every day 9 , is of particular interest for social scientists because of the huge availability of brief messages - up to 140 characters - made public online representing an unprecedented opportunity to study human communication and interaction. Indeed, Twitter enables users to stay informed and up-to-date on topics of interest by 'following' other users, as well as to share their contents with their 'followers' in real time. Twitter also encourages interaction between users thanks to the possibility to invite someone to join a conversation, or simply to draw his/her attention to a specific tweet by putting @ before the account name of the person they wish to attract. One can also express support or agreement on another's tweet by 'retweeting' (RT) it, with the aim of sharing it with his/her own followers. In addition to these interesting aspects, one of the main attractions for social scientists is probably the 'hashtag' function, i.e. the possibility to tag a word included in the tweet in order to make it visible and traceable through Twitter's search function.

Since, as previously said, in the real world it seems impossible to measure interactions between systems and sub-systems, we propose to reduce our field of research to Twitter. Indeed, for the purposes of this research Twitter can be considered as a sample of the real world in which is possible to measure the interaction between elements belonging to different systems and sub-systems. Every Twitter user must in fact communicate in a given code $£^{10}$ (a message of a maximum of 140 characters with the possibility to insert pictures or link to

\footnotetext{
${ }^{6}$ One of the main results concerns employment status since interns are not generally entitled to protection if they are considered volunteers whereas they are protected if they are considered employees.

${ }^{7}$ For an overview of labour market institutional characteristics see (Blampain, 2014).

${ }^{8}$ See Section 3.

${ }^{9}$ Source: http://about.twitter.com/company.

${ }^{10}$ In addition to the general rule of up to 140 characters per message there is also a specific language to express a concept
} 
websites) and it is possible to trace every message of every user. Hence, it can therefore be argued that Twitter can show and keep track of impulses between different systems and sub-systems.

Social sciences recognised the potential of this tool for research purposes early, investigating a wide range of aspects which often fall into the category of 'sentimental analysis' which counts over 7,000 articles, hundreds of start-ups and statistical packages (such as SAS and SPSS) including dedicated sentiment analysis tools (Feldman, 2013). Twitter itself created an account in June 2013 named @twitterdata 11 which is specifically aimed at reporting and representing (often visually through interactive maps) results coming from the incredible flow of Tweets published every second on hot topics throughout the world 12 .

Social media (and Twitter in particular) are widely used for commercial purposes (market research, viral marketing, market analysis and customer intelligence (McKinsey, 2011); they have also been used in the field of behavioural sciences for the analysis of human behaviour and social networks (Dodds et al., 2011). Recently, Twitter data has mainly given rise to sentiment analysis and communication studies, analysing the topics of happiness (Dodds et al. 2011), social networks (Cha et al., 2010) and the relationship with traditional media (Jisun et al., 2011).

Research using social media has therefore stressed above all the private sector or focused on sociologicalbehavioural analysis, but, rarely, on the public sector.

With regards to the latter, research has mainly developed analyses of macroscopic socio-economic events, such as the aspects of communication related to politics (e.g. the US presidential elections (Conover et al. 2011), or has analysed their role in terms of democratisation or support of social change: from the Arab spring (Aday et al., 2010), to the presidential elections in Iran (Aday et al., 2010) or Egypt (Amel, 2012) to British unrest during the summer of 2011 (Guardian, 2011) and, more recently, the unrest in Ukraine.

Other studies have shown the effects of social media in increasing the efficiency of public administration, but only from an 'operational-organisational' point of view in terms of cost reduction and transparency.

The consequences social media can have in terms of bilateral relationships from the institution to the individual and, vice versa, from the individual to the institution in terms of feedback, knowledge and decisionmaking processes have, however, rarely been investigated. Evidence has also shown how the public sector does not fully make use of the opportunities afforded by information generated (or that could be generated) through social media, especially in terms of the creation and maintenance of laws and norms and policy making 13 . In this analysis we attempt to fill this gap and assess the possible use of Twitter as a policy tool and as an instrument suitable for analysing smaller-scale phenomenon as well, not only macroscopic events.

From a methodological point of view, social science literature on social media lies on the border with

with abbreviations, acronyms or Twitter-related words. For some examples see the so-called "Twittonary" in http://www. twittonary.com

${ }^{11}$ Cf. https://twitter.com/TwitterData.

${ }^{12}$ See, as example, the number of Tweets on the EU election in the UK, @TwitterData, How \#Elections2014 played on Twitter\#animation \#map in http://cdb.io/1obYEQJ. In order to give an idea of the number of Tweets available on the topic, during the 2014 FIFA World Cup in Brazil 672 million Tweets were published (http://www.theguardian.com/technology/2014/ jul/15/twitter-world-cup-Tweets-germany-brazil).

${ }^{13}$ Just as an example, Twitter could be considered as a way to measure the impact of a new law in order to understand its pros and cons or elements to be improved. 
computer science, since automated content analysis has, for the most part, overcome manual analysis King and Lowe, 2003). This literature has, however, outlined the limits of machine learning techniques and natural language processing (NLP) in understanding and detecting all shades of human speech, especially when it is as concise or mangled and multi-faceted as 140-character Twitter language (Procter et al., 2013).

In this context, our experimentation based on Twitter does not aim to analyse interaction and communication models per se (Faust and Wasserman, 1994), nor idoes it attempt to profile users of social media (Sloan et al., 2013) or to examine the 'physical shape' of social relationships on Twitter or provide an instant picture of a certain hot topic.

This research aims instead to discover information concerning certain policy and legal provisions with a bottom-up approach, i.e. by collecting perceptions directly from the recipient of that norm or policy, in order to make an initial attempt to use Twitter as a form of connection within the public sphere, and, specifically, between a legislator or policy maker and the persons on which a particular law or policy has an impact. Establishing a gateway between the two sub-systems could contribute, on a wider scale, to bridging the detachment which exists between the policy maker and the policy recipient. Hence it seems possible that, through the rational use of social networks, people from social systems or sub-systems might be able to influence the legal system simply by expressing their ideas and without recourse to huge protests.

In this view, unlike the approach taken by sentiment analysis (based on large datasets), we decided to analyse internships not only, as mentioned earlier, because they make up one of the areas in the labour market affected by a particularly high level of inequality, with a good chance of finding people willing to express their views, but also for other three further reasons.

Firstly, the fact that the internship is a broad, widely recognisable but heterogeneous concept; it is understood in a general sense as a temporary study/work (or 'sandwich') experience accompanying most young people's entrance into the worldwide labour market:14, however, there is a great amount of variance between countries in the way in which traineeships are regulated. This provides a good way of investigating how different legal systems can impact on young people's perceptions of the experience.

Secondly, the internship, regarding only young people, is a well-known but narrow topic (Tweets written by work agencies and other job advertisements were discarded from the analysis), reducing notably the variance in individual characteristics, at least in terms of age group and labour market status.

Thirdly, the fact that internships have long been seen as a means of exploiting the vulnerability and precariousness of young people renders it an issue worth investigating and bringing to people's attention 15 .

In doing so, this research attempts to use Twitter in order to derive information regarding the perceptions that young people - as direct users - have of internships, trying to understand whether (on average and based on preliminary evidence) this tool is considered by young people as positive or negative and if common differences in evaluations of internships can be observed in different legal systems/countries, thus possibly leading to certain suppositions in terms of policy and institutions.

\footnotetext{
${ }^{14}$ For an overview of different types of internships see Maertz Jr et al. (2014).

${ }^{15}$ Several campaigns for the protection of interns' rights have been conducted by internship organisations. See, for an example Heath and Potter (2011), Lyons (2013).
} 
Given the limits of automated content analysis, this project relies on the manual coding of Tweets, as in the trade-off between the dimension of the sample and its accuracy, we believe that manual coding brings greater gains in such an analysis. Indeed, young people's style of communication, especially when using a 140-character Tweet, is rather succinct and could be easily misunderstood by automatic analysis. Besides methodology caveats, the use of Twitter as a database has other limits (Mislove et al., 2011) connected to the sample composition and to a possible lack of representativeness. In fact, Twitter is mostly used by people who are comfortable with technology and mainly liberal (Jisun et al., 2011). However, by focusing on traineeships, a topic concerning almost exclusively the young, we believe it possible, as previously noted, to limit (at least partially) this bias.

Furthermore, this analysis aims to go beyond the representation of data, including an econometric analysis of the observations. In this framework, hashtags, the key words used in Twitter to tag topics indicated the \# symbol, might constitute the aforementioned gateways through which it may be possible for different systems to communicate one with each other.

The main focus of the analysis concerns young people's perceptions of internship: ${ }^{16}$. Young people experiencing an internship are in fact those on which regulatory rules on this topic exert their direct effects, often with striking differences depending on different legislations (mandatory payment or possibility to do an unpaid internship, for example). In this way, young people represent a possible bottom-up source for legislators, potentially able to impose themselves as a gateway to the legal system. This model aims to set the basis for a law-maker 2.0, a more inclusive, innovative and reflective institution, capable of putting social justice at the top of the agenda by fulfilling the real needs of the parties involved through 'I-Thou' relations.

\section{Methodology}

We estimate the following model

$$
\begin{aligned}
y_{i} & =\beta_{0} x_{i}+d M+\mu_{0 i} \\
E\left[\mu_{0 i}\right] & =0 \\
\operatorname{Var}\left[\mu_{0 i}\right] & =1
\end{aligned}
$$

where $y$ is a dummy variable taking the value 1 if the respondent perceived his/her internship as a positive experience and 0 otherwise. $x$ is a vector of covariates, including: gender, age, country of residence and country where the internship was displaced. $\mu$ is the error term and $d$ and $\beta$ are coefficients. $\mathrm{d}$ is a measure of the impact of gender on perceived valuation. Given that $M$ is a dummy variable, the marginal effects (ME) of the

\footnotetext{
${ }^{16}$ In literature there are many studies analysing youth perceptions of internships (Cook et al. 2004, D'abate et al., 2009, Gupta et al., 2010, Henry, 1979, Hurst and Good, 2010, McCaffery, 1979, Narayanan et al., 2010) but each of them has been based on surveys where the young people were aware that they were releasing information for research and they have been conditioned. This research, however, is based on information that has been given indirectly by young people without them noticing the data collection.
} 
presence of minimum wage regulation on the probability of perceiving the internship as a positive experience is the sample average of changes in the marginal predicted probability of a positive perception with discrete changes in $M$ keeping all other variables $x$ at their observed values.

$$
M E=\frac{1}{n} \sum_{i=1}^{n}\left[\left(\Phi\left(\hat{\beta}_{0} x_{i}+\hat{d} M_{i} \mid M=1\right)-\Phi\left(\hat{\beta}_{0} x_{i}+\hat{d} M_{i} \mid M=0\right)\right]\right.
$$

where $\Phi$ is the standard normalised distribution function and $\Phi\left(\hat{\beta}_{0} x_{i}+\hat{d} M_{i}\right)$ marginal predicted probability of having a positive perception of the internship and is computed for each observation using the estimated coefficients; $n$ is the number of individuals in the sample.

\section{Data}

The sample is composed of observations retrieved from the social network Twitter from January 2013 to January 2014. The observations were collected in order to examine perceived evaluations directly expressed by interns from different countries. Twitter is designed to trace any discussion regarding a particular topic using hashtags (indicated with \#), so, for our purpose, we decided to collect observations under the following hashtags: \#intern, \#internship, \#practica(s), \#praktik, \#praktika, \#praktikant, \#praktikum, \#stage, \#tirocinio, \#trainee, \#traineeship, \#utplassering.

In order to asses the perceived quality of internships as expressed by young people we read all the Tweets under these hashtags (with no automatic analysis of Tweets) and drew from them the evaluation, categorising it as positive or negative ${ }^{17}$. Whenever a Tweet was too vague to be categorised we dropped the observation. The translator function available on Twitter was used to translate the Tweets from different languages into English.

The variables included in the model to explain young people's evaluations of internships (positive versus negative) are those connected to national regulations and norms, proxied by the country explanatory variable. By controlling the country where the internship is placed we expect to register variation in terms of institutional labour market variables (rigidity of employment protection for temporary contracts and minimum wage, as well as specific characteristics of internships such as duration, existence of mandatory pay and so on), as well as in terms of the more general heterogeneity existing across economies. Where available, the economic sector in which the internship takes place has been included as an additional control. In order to account for individual characteristics we also included information about gender, (approximate) age of individua 18 , nationality, day of Tweet.

Other information available on Twitter - the number of Following and the number of Followers - has also

\footnotetext{
${ }^{17}$ An example of this evaluation from two collected Tweets, respectively categorised as positive and negative: example 1: @kittyyykait: "Always feel so good about the work at @YearUpPRO \#success \#intern"; example 2: @JoelSalvino: I don’t understand how you can expect me to work but not pay me. I GOTTA EAT! \#internship \#studentdebt \#neverpay \#debtstrike".

${ }^{18}$ Age is not a mandatory field in Twitter, therefore only in the minority of Tweets was it possible to establish the exact age of the individual. Based on indirect information, it was only possible to distinguish individuals as younger or older than 18.
} 
been reported to provide a proxy for the influence, activity and interaction levels of the user.

\section{Results}

The sample (Table 1) is composed of 505 young individuals (30\% male and $70 \%$ female). Concerning geographical composition, the data mostly reflect opinions of young Europeans (83\%), who represent the vast majority of our sample, coming from Italy, Holland, the United Kingdom, France, Germany, Sweden, Norway, Spain and Denmark; however, the data also contain information on the United States (17\%).

[Table 1 about here.]

Data show that more than half of the sample (290 vs. 148) perceive their internship as a positive experience.

[Figure 1 about here.]

Based on the categorisation of Tweets in positive versus negative evaluation, Figure 1 shows how perceptions vary across European countries. Perceptions are on average more likely to be positive (in darker colours on the map) in the United Kingdom and Spain, followed by Germany, the Netherlands and Sweden. Perceptions are, on the other hand, more likely to be negative (in lighter colours) in Italy and France.

Sorting all our (relevant) statistics by perceived evaluations, after a T-test (Table 2), we observe that:

- age differences in perceived evaluation are not statistically significant;

- gender differences in perceived evaluation are statistically significant, with men reporting worse perceptions of internships than women;

- country-based differences in perceived valuation are statistically significant in: Italy, the United Kingdom, France, Spain and Unites States;

- apart from medical and professional sectors, all sector-based differences in perceived valuation are statistically significant.

Using the model presented above, an econometric analysis was conducted in order to test for the existence of a relationship between the explanatory variables and the probability of a positive versus a negative evaluation of the internship experience by young people.

[Table 2 about here.]

Table 3 presents the coefficient and Marginal Effects (ME) for the univariate Probit model. Confirming the T-test, the variable associated with gender is always significant and negative, highlighting the fact that males, on average, are less inclined to perceive their internships as a positive experience, even after making allowance for the country of origin and for the economic sector (where available). Age, as expected, is not significant in any specification. 
[Table 3 about here.]

The country variable, indicating the country where the internship is placed and used in this analysis as a proxy of the legal system governing the labour market, is always significantly connected to the perception of internships. More specifically, the probability of a positive evaluation of the internship experience is higher if the internship is placed in the Netherlands, the United Kingdom, Germany, Spain and the United States; on the contrary, doing an internship in Italy and France is connected to a higher probability of having a bad experience or at least giving a negative evaluation.

Are men less likely than women to appreciate internships because of differences within or between the two groups? What is behind the generally higher probability of finding better opinions of internships in liberal countries, and more negative ones in countries like Italy and France?

\subsection{Within-Gender of Across-Gender Differences: The Blinder-Oaxaca Decomposition}

In order to understand whether differences in perceived evaluation between gender resulting from the previous regression are due to within- or across-gender differences we used a technique well-known in labour economics, the Blinder-Oaxaca decomposition (Blinder, 1973, Oaxaca, 1973, Oaxaca and Ransom, 1994).

The Blinder-Oaxaca methodology allows us to decompose the magnitude of the differences in an average population into portions relating to discernible differences in the composition of the population and portions relating to 'genuinely' different reactions. Assuming that there are two groups, A and B, an outcome variable $\mathrm{Y}$ and a set of regressors ${ }^{19}$ as in our case. The question is how much of the difference in mean outcome

$$
R=E\left(Y_{A}\right)-E\left(Y_{B}\right)
$$

is accounted for by group differences in the regressors.

Based on the linear model

$$
Y_{l}=X_{l}^{\prime} \beta_{l}+\epsilon_{l} \quad E\left(\epsilon_{l}\right)=0 \quad l \in(A, B)
$$

where $X$ is a vector of country group indicator variables, $\beta$ contains the slope parameters and the intercepts and $\epsilon$ is the error term, the mean outcome difference can be expressed as the difference in the linear prediction at the group-specific means of the regressors. That is ${ }^{20}$

$$
R=E\left(Y_{A}\right)-E\left(Y_{B}\right)=E\left(X_{A}\right)^{\prime} \beta_{A}-E\left(X_{B}\right)^{\prime} Y_{B}
$$

To identify the contribution of group differences in predictors to the overall outcome difference, (5) can be

\footnotetext{
${ }^{19}$ For example, think of a group of males and a group of females, (log) wages as the outcome variable, and human capital indicators such as education and work experience as predictors.

${ }^{20}$ Since $E\left(Y_{l}\right)=E\left(X_{l}^{\prime} \beta_{l}+\epsilon_{l}\right)=E\left(X_{l}^{\prime} \beta_{l}\right)+E\left(\epsilon_{l}\right)=E\left(X_{l}\right)^{\prime} \beta_{l}$ where $E\left(\beta_{l}\right)=\beta_{l}$ and $E\left(\epsilon_{l}\right)=0$, by assumption.
} 
rearranged, for example, as follows:

$$
R=\left\{E\left(X_{A}\right)-E\left(X_{B}\right)\right\}^{\prime} \beta_{B}+E\left(X_{B}\right)^{\prime}\left(\beta_{A}-\beta_{B}\right)+\left\{E\left(X_{A}\right)-E\left(X_{B}\right)\right\}^{\prime}\left(\beta_{A}-\beta_{B}\right)
$$

which is a 'threefold' decomposition, that is to say, the outcome difference is divided into three components:

$$
R=E+C+I
$$

1. The first component

$$
\left\{E\left(X_{A}\right)-E\left(X_{B}\right)\right\}^{\prime} \beta_{B}
$$

accounts for the part of the differential due to group differences in regressors (i.e. endowment effects);

2. The second component

$$
E\left(X_{B}\right)^{\prime}\left(\beta_{A}-\beta_{B}\right)
$$

measures the contributions of differences in the coefficients.

3. The third component

$$
\left\{E\left(X_{A}\right)-E\left(X_{B}\right)\right\}^{\prime}\left(\beta_{A}-\beta_{B}\right)
$$

is an interaction term accounting for the fact that differences in endowments and coefficients exist simultaneously between the two groups.

In equation (6) the first term will indicate the amount of variation in population averages due to differences in the characteristics of the two genders (i.e. within gender differences).

The second term reflects the amount of the change in population averages that is attributable to differences between coefficients (i.e. across-gender differences).

Finally, the third term corresponds to the interaction between changes in frequency of the group and the average perception within that group.

A change mostly due to the first term will imply that the difference in perceived evaluation is above all due to demographic characteristics specific to each gender that may be behind different views; while a change mostly due to the second term will imply a differential due to external and commonly environmental causes which cannot be related to individuals' specific characteristics.

Our estimation of equation (6), reported in Table 4, shows that both across- and within-group changes contribute positively to the difference in the dependent variable (evaluation of internship) and that the second term dominates.

[Table 4 about here.]

Indeed, we find that more than $90 \%$ of the difference in the evaluation of internships can be tied to characteristics common to both genders. Thus the reported difference in perceived valuation cannot be 
related to gender-specific characteristics but to common factors yet to be determined

This conclusion highlights the importance of the social and judicial context in which internships are included in determining their importance in respondent's careers.

\subsection{Within-Gender or Across-Gender Differences: The Fairlie Decompostiion}

In addition to the Blinder-Oaxaca decomposition, we employed a second decomposition strategy as an additional analysis to examine in greater detail the within- or across-gender differences in internship evaluation. We employed the Fairlie decomposition technique as it is supposed to be more suitable in order to calculate gaps for binary variables, as our dependent variable is (Fairlie, 2005).

The decomposition for a non-linear equation of the type $p(y=1)=F(x \hat{\beta})$ can be expressed as:

$$
\bar{y}^{W}-\bar{y}^{M}=\left[\sum_{i=1}^{N^{W}} \frac{F\left(x^{W} \hat{\beta}^{W}\right)}{N^{W}}-\sum_{i=1}^{N^{M}} \frac{F\left(x^{L} \hat{\beta}^{W}\right)}{N^{M}}\right]+\left[\sum_{i=1}^{N^{M}} \frac{F\left(x^{M} \hat{\beta}^{W}\right)}{N^{M}}-\sum_{i=1}^{N^{M}} \frac{F\left(x^{M} \hat{\beta}^{M}\right)}{N^{M}}\right]
$$

where $\bar{y}_{i}$ is the average perceived probability for individual $j(j=W, M$ for women and men, respectively), $x_{j}$ is the set of average values of the independent variables used for individual $j$ (e.g. age, country of residence and country where the internship took place), $\hat{\beta}_{j}$ is the coefficient estimated for $j, F$ is the cumulative distribution function from a standard normal or a logistic distribution and $N$ refers to the sample size in each period.

Unlike the threefold Blinder-Oaxaca decomposition, in this case we have a twofold decomposition. The first term in brackets in equation (11) shows the part of cross-gender difference due to group differences in the distribution of characteristics of the $x_{j}$, referred to as the 'explained part', while the second term in brackets represents the portion of the differences due to differences in coefficients of the exogenous covariates but also represents differences in impalpable endowment, and is thus referred to as the 'unexplained part'. Similarly the non-linear decomposition can be written as:

$$
\bar{y}^{W}-\bar{y}^{L}=\left[\sum_{i=1}^{N^{W}} \frac{F\left(x^{W} \hat{\beta}^{M}\right)}{N^{W}}-\sum_{i=1}^{N^{M}} \frac{F\left(x^{M} \hat{\beta}^{M}\right)}{N^{M}}\right]+\left[\sum_{i=1}^{N^{W}} \frac{F\left(x^{W} \hat{\beta}^{W}\right)}{N^{W}}-\sum_{i=1}^{N^{W}} \frac{F\left(x^{W} \hat{\beta}^{M}\right)}{N^{W}}\right]
$$

where in this case the estimated coefficients for men $\hat{\beta}^{M}$, are used as weights to calculate the first term of the decomposition, and the women's distribution of average characteristics is used as weights for the second term. Given that the two decompositions in Equations (11) and (12) provide different estimates, to avoid this problem we used the coefficient estimates from a pooled sample over all cases to weight the unexplained part of the decomposition.

Equations 112 and 12 provide an estimate of the contribution of the explained and unexplained parts to the total difference between the two periods. These decompositions cannot be rewritten in order to match

\footnotetext{
${ }^{21}$ Also in Smayling and Miller (2012) gender did not seem to play a role in the students' view of the value of various work characteristics.
} 
the threefold ones derived earlier, and we will therefore concentrate on the single contributions of individual independent variables, paying particular interest to those of social justice.

The calculation of the separate contributions of the individual independent variables (or groups of covariates) is not direct. One has to assume that $N^{m}=N^{W}$ and $\hat{\beta}^{*}$ is the Probit coefficient estimated from a pooled sample. The individual contribution of regressor $x_{k}$ to the cross-gender perceived difference can then be written as

$$
\frac{1}{N^{M}} \sum_{i=1}^{N^{M}} F\left(\hat{\alpha}^{*}+x_{k i}^{W} \hat{\beta}_{k}^{*}+\sum_{m \neq k} x_{m i}^{W} \hat{\beta}_{m}^{*}\right)-F\left(\hat{\alpha}^{*}+x_{k i}^{M} \hat{\beta}_{k}^{*}+\sum_{m \neq k} x_{m i}^{W} \hat{\beta}_{m}^{*}\right)
$$

which means that the contribution of a particular variable to the difference is calculated by holding constant the contribution of the other variables ${ }^{22}$. Notice that the computation of equation 13 involves a one-to-one matching of cases between the two groups $\left(N_{W}>N_{M}\right)$ and, as they typically differ in size, a large number of random sub-samples from the larger group are drawn. Each of these random sub-samples of the early sample is then matched to the later sample and finally separate decomposition estimates are calculated. The mean value of estimates from the separate decomposition is calculated and used in order to derive the results for the entire early sample.

Table 6 displays Fairlie's decomposition from which we can see that our covariates are able to explain almost $20 \%$ of the overall difference in perceived evaluation between men and women. This result might seem a very low one, but we have to bear in mind that we are not relying on self-reported variables from a survey but from variables self-collected directly from Twitter and this attempt to establish this as a reliable survey method is a preliminary one.

[Table 5 about here.]

In line with the results from our Blinder-Oaxaca decomposition from Section 5.1 we find that almost $70 \%$ of this explained difference in gender specific satisfaction is due to the legal system in which the respondent performed his/her internship (column (2) Table 5). When we do not include such a covariate our model explains less than $10 \%$ of the gender difference (column (1) Table 5), while when we add it we are able to explain almost $20 \%$ of the gap (column (2) Table 5).

To further investigate this result we carried out a different decomposition between Liberal and NonLiberal countries ${ }^{23}$ (columns (3)-(5)) in order to understand whether the difference in evaluations between the two systems could be related to their different legal framework, and, in particular, to the different levels of rigidity of temporary work regulations. We included two indicators to classify the stringency of regulation: (1) the employment protection legislation index on temporary contracts from the OECD and (2) an internship regulation strictness index that we constructed (Table 8). Without any of these covariates (column (3)

\footnotetext{
${ }^{22}$ See Fairlie (2005) for a further discussion on how to compute standard errors.

${ }^{23}$ We used Liberal countries as a benchmark since they have an over-the-mean internship satisfaction rate (82\% vs. 60\%). The Liberal/Non-Liberal differences are explained in more depth in Section 5.4.
} 
Table 6) the model is unable to predict any of the differences between the legal systems. When we add the temporary protection of workers index from OECD and our index (column (4) and (5) Table 5) we are able to predict respectively more than $90 \%$ and more than $50 \%$ of such a gap. Since both covariates enter the estimation with a significant and negative result we argue that the stricter the temporary work protection, the less the individual is satisfied. This may be related to the fact that very cumbersome regulations can create friction in the search and matching of employees and employers, making it more difficult to undergo a positive experience due to greater difficulty in complying with a very strict legal standard rendering the working experience less stimulating and formative and more cumbersome.

Such results shed some additional light on the main factors in internship satisfaction which turn out to be related not only to the legal system, and hence the country where the internship takes place, but also to the specific and unique degree of rigour that each legal system has towards temporary work protection. We are not arguing that an absence of any regulation will achieve a higher level of satisfaction, but that there could be an optimal level of temporary working protection/strictness, which may be the one that we observe in liberal countries.

\subsection{Labour Market Conditions for Young People}

Before trying to explain differences between countries from a legal perspective, it may be useful to give an overview of the situation of young people in the labour markets in the European countries concerned 24.

[Figure 2 about here.]

Figure 2 represents the share of young people not in employment, education or training (NEET), one of the most significant indicators of the difficulty in the labour market experienced by young people25. Italy and Spain are among the European countries hit hardest by the crisis where young people are disproportionately affected by inactivity and loss of trust 26 . NEET rates for young people aged from 15 to 29 years reached $26 \%$ in Italy and almost 23\% in Spain in 2013 (Figure 2).

[Figure 3 about here.]

Similarly, as Figure 3 shows, youth unemployment rates vary greatly across countries. Youth unemployment is dangerously high in southern European countries, especially in Spain (55.5\%) and Greece (58.3\%), but also in Italy (40\%) and Portugal (37.7\%). Conversely, youth unemployment is lower than $10 \%$ in Germany $(7.9 \%)$, Austria (9,2\%), Norway (9.1\%), Switzerland (8.5\%, source: Eurostat) and below $20 \%$ in the Netherlands (11\%) and Finland (19.9\%), while it is slightly higher than $20 \%$ in the United Kingdom (20.5\%) and France $(23.9 \%)$ and Belgium (23.7\%). In other developed non-European countries, the youth unemployment rate

\footnotetext{
${ }^{24}$ On this topic see Tiraboschi $(2014)$.

${ }^{25}$ See ILO (2014).

${ }^{26}$ This issue has been addressed also at communitarian level, see Council of European Union, Conclusions on enhancing the social inclusion of young people not in employment, education or training, February 1st 2014, No. 2014/C 30/03, available at http://eur-lex.europa.eu/legal-content/EN/TXT/PDF/?uri=CELEX : 52014XG0201(02)\&from=EN.
} 
in 2013 was $12.2 \%$ in Australia, $13.7 \%$ in Canada, $6.9 \%$ in Japan, $15.8 \%$ in New Zealand and 15.5\% in the United States (source: OECD). As data shows, it is arguable that intuitively, and without assuming any causal relations, young people's perceptions of internships could be influenced, as well as by individual and institutional factors, by the general situation of young people in the labour market.

\subsection{Institutional Determinants of the Perceptions of Internships}

Assuming that perceptions of internships may be influenced by the country where the internship is placed and, consequently, by its legal system, and having observed the explanatory power of the Liberal covariate, we tried to explain differences in the perceived evaluations by looking at different legal systems, stressing the differences between Liberal and non-Liberal countries. Indeed, as previously shown by the Probit analysis, both the United Kingdom and the United States individually and the welfare type 'Liberal' were estimated to be connected to a higher probability of young people giving positive perceptions of internships, differently from other countries such as Italy and France that were linked to a lower probability of observing positive evaluations of internships. Going beyond the Liberal and Non-Liberal clusters, countries have also been grouped by welfare-state type, according to the well-known Esping-Andersen social welfare system classification (Esping-Andersen, 1990), forming four groups: Christian Democratic (Germany, the Netherlands, France), Liberal (United Kingdom and United States), Mediterranean (Italy, Spain) and Social Democratic (Sweden). When clustering countries by welfare type, this institutional determinant of the perception of internships becomes no longer significant, except for the Liberal countries, where it remains positively and significantly connected to a higher probability of expressing a positive perception of internships (maximum level of statistical significance).

Given the differences across countries and welfare regimes in the probability of perceiving internships as a positive experience, we tested for the hypothesis that the general employment protection legislation on temporary contracts (a measure of the difficulty the employer has in hiring on a temporary basis) may play a role in determining the use or abuse of the internship tool, and thus influencing the evaluations given by of interns. Indeed, several studies 27 have pointed out how too rigid employment protection legislation could increase the risk, especially for workers on the margins of the labour market (young people and women), of being employed on a temporary basis and with flexible contracts. If employers are hindered in hiring young people because of stringent regulations, we could assume where rigid norms regulating entrance into the labour market exist, employers may avoid them by substituting regular temporary work contracts with noncontractual, flexible arrangements such as internships. The use of internships and traineeships as substitutes for regular work represents an abuse of these instruments which are intended as training tools for the transition from school to work 28 . In turn, such abuse may hinder the training and educational value of internships, and,

\footnotetext{
${ }^{27}$ For a review of labour regulations in 85 countries see Botero et al. (2004). For the analysis of the employment protection legislation on labour market indicators see Bentolila et al. (1994), Bertola et al. (2007), Boeri and Garibaldi (2007).

${ }^{28}$ See Council of European Union, Recommendation of 22 April 2013 on Establishing a Youth Guarantee, April 22nd 2013, No. 2013/C 120/01, available at http://eur-lex.europa.eu/legal-content/EN/TXT/PDF/?uri=CELEX:32013H0426(01)\&from=EN Council of European Union, Conclusions of 11 May 2012 on the employability of graduates from education and training, May 11th
} 
given the fact that they are often unpaid and unprotected, they may be seen by young people as a means of exploitation 29

[Figure 4 about here.]

[Figure 5 about here.]

In order to test the hypothesis that the probability of young people giving a positive versus negative perception of internships may be also connected to general employment protection legislation on hiring, we included the Employment protection legislation on temporary work index produced by the OECD.

The OECD Employment protection legislation (EPL) indicator (reported in the bar chart in Figure 4 and in the Map in Figure 5) synthesises the strictness of regulation of temporary work, ranging from zero (least regulated) to 5 (most regulated). This index proxies the extent to which it is easy for employers to hire people along dimensions related to fixed-term contract:30 and temporary work agencies (TWA)

As shown in Table 6, by including the index on employment protection legislation on temporary work in the Probit regression we have a significant negative indication, suggesting that the more rigid the regulations on hiring in a country, the lower the probability of observing positive perceptions of internships for young people in the same country. Other co-variates representing individuals and legal systems give the same results as before, confirming the role of national legal systems and welfare regimes.

[Table 6 about here.]

\subsection{Internship Regulation Index}

[Figure 6 about here.]

After having tested the hypothesis that the strictness of the labour market regulation on temporary contracts may influence the perception of internships we would like to provide a sensitivity test by creating an index to represent the strictness of internship regulation in order to provide a specific parameter more suitable for the purpose of our research.

2012, No. 2012/C 169/04, available athttp://eur-lex.europa.eu/legal-content/EN/TXT/PDF/?uri=CELEX:52012XG0615(04) \&from=EN Council of European Union, Conclusions of the Council and of the Representatives of the Governments of the Member States, meeting within the Council of 21 November 2008 on youth mobility, December 16th, 2008, No. 2008/C 320/03. In the literature cf Shoenfelt et al. $(2013)$.

${ }^{29}$ Concerning the negative effects of unpaid internships see Durrant (2013) who asserts that "the adverse consequences of unpaid internships include financial detriment to interns, discriminatory benefits among different socioeconomic classes, an increase in the unemployment rate, and a lack of workplace harassment statutes protecting interns".

${ }^{30}$ Such as the valid cases for the use of fixed-term contracts, a maximum number of successive fixed-term contracts, maximum cumulated duration of successive fixed-term contracts.

${ }^{31} \mathrm{Such}$ as the types of work for which temporary work agency employment is legal, restrictions on the number of renewals of TWA assignments and, only available for 2008-2013 period: maximum cumulated duration of TWA assignments, authorisation or reporting obligations; equal treatment of regular and agency workers at the user firm. 
Using official data available on the government websites of the analysed countries and in EU comparative material, we created an index based on six parameters that seem relevant in defining the strictness of regulation for internships. We assumed that the level of rigidity is higher if pay is mandatory ${ }^{32}$, if the maximum duration is 6 months or less; if there are age limits; if there is specific legislation on internships; if it is possible to be engaged in an internship only while in education; and if it is mandatory to sign a written agreement.

The index is by the sum of each element, with 0 (if none of the conditions are met) revealing a complete absence of regulations on internships and 6 (if every condition is met) being the maximum level of strictness of internship regulation. The numbers thus obtained are then rescaled in three categories of strictness: from 1 to 2 , to be considered as a 'deregulated system'; from 2 to 4 to be considered as an 'averagely regulated system 33 and from 4 to 6 , a 'strictly regulated system'. According to this exemplification, Italy is the country where there is the strictest regulation of internships since the only condition of strictness that is not met is the possibility of being engaged in internships only during education patterns as 'open market' internships are allowed. At the opposite end of the scale the United Kingdom and the United States appear as the least regulated countries in this aspect since none of the conditions are met.

As expected (Table 7), the Internship Regulation Index (IRI) trend is similar to the trend of the OECD indicator on the rigidity of employment protection legislation on temporary contract 34 reflecting the general strictness of the labour market regulatory framework. However, the Internship Regulation Index is nonetheless useful as a robustness check in order to have another element confirming the above mentioned intuition that a stricter regulation may lead to misuse.

[Table 7 about here.]

[Table 8 about here.]

In this case we can assume that the rigidity of elements such as mandatory pay, maximum duration, age limits, education scope, and mandatory written agreements may be seen as an obstacle from employers and that they might therefore try to avoid restrictions by misusing internships. Such behaviour, especially in countries with rigid employment protection legislation, may come about due to the fact that internships, despite being regulated, are still less rigid than employment contracts.

On the other hand, in countries where internships and temporary employment contracts are less regulated, employers can choose the contract that best fits their needs and do not have to recur to internships solely as a way to avoid law restrictions.

\footnotetext{
${ }^{32}$ The issue of payment for internships is highly debated. Cf. the research of Beebe et al. (2009). While the survey conducted in Rothman (2007) shows that payment in internship is not a an essential point, since there are other elements that may be more important in an internship experience, such as a clear understanding of what the employer wants the intern to accomplish, challenging assignments, a reasonable time-frame for accomplishing tasks, meaningful feedback etc.

${ }^{33}$ Traineeships are comprised in the more general Vocational Education and Training (VET) framework.

${ }^{34}$ Even if those indexes are calculated in different ways since the latter is based on a standard-scale and the Internship Regulation Index (IRI) is made only by the sum of all parameters.
} 


\section{Conclusions}

One possible explanation for the different results observed between liberal and non-liberal countries in terms of the probability of observing a positive evaluation of internships by young people may lie in differences in labour market institutions.

The covariate 'rigidity of employment protection legislation on temporary contracts' (an index created by the OECD and summarising the extent to which it is difficult for an employer to hire on a temporary basis) does indeed report a negative and significant coefficient $\left(-0.244^{* * *}\right)$ indicating the possible role of the more general employment protection legislation framework in the probability of observing positive versus negative perceptions of internships. According to this intuition, the more difficult it is to hire on a temporary basis in a country, the lower the probability of observing positive evaluations.

The same trend can also be seen by analysing the newly-created Internship Regulation Index, which measures the rigidity of internship regulations. According to the obtained results, stricter regulations on internships are not a guarantee of their genuine use, training and educational capacity as they are indeed connected to a lower probability of internships receiving a positive evaluation from young people.

Two hypotheses could explain these possible relationships: one concerning demand and the other concerning supply. Regarding labour demand, employers operating in an extremely regulated environment with a high level of rigidity of employment protection legislation on temporary contracts may be induced to use internships as a form of hiring flexibility instead of regular or standard employment contracts. This would in practice distort the use of an internship, changing its nature from a training tool to a low-cost and highly flexible contract thus increasing the probability of young people perceiving it as a negative experience. As for labour supply, young people in Liberal countries are more used to internships and other school-to-work transition schemes with respect to highly regulated labour markets, and are therefore more likely to provide more positive evaluations.

Another reason in addition to the institutional framework may lie in the more general situation of young people in countries like the United Kingdom and the United States with respect to Italy or France. In the face of the economic crisis that is still affecting young people, they may decide to undertake internships as a way out of unemployment, thus also accepting low-quality traineeships (unpaid, little training, not coherent with studies or previous experience and so on), and/or repeating multiple internship experiences, which may be seen as dead-end jobs rather than stepping stones to more permanent positions. 35 .

The existence of stricter labour protection legislation, combined with the higher labour cost of employment contracts and a 'first study and then work' school-to-work transition model may all be connected to the negative feedback coming from young interns in Italy and France compared to those living in countries with a Liberal system.

Moreover, young people's perceptions as evidenced by this research seem show that a higher level of regulation of internships might not be an effective method for the protection of interns' rights or for guaranteeing

\footnotetext{
${ }^{35} \mathrm{See}$, for example, the difference in the number of applications for internships at the European Commission where the numbers of applicants from Italy is considerably higher than the number of applicants from Germany or France. Cf. Fazio (2013).
} 
'high quality' internships, leaving room for the possible existence of more important factors determining internship quality, such as training and human capital investment. Obviously, as previously explained, it is necessary to take into account several elements prior to establishing whether the strictness of regulations governing internships influences perceptions of them, but this research would nonetheless like to propose a possible key to interpreting the young people's opinions.

Being aware that the data set used is not enough to provide policy suggestions, the model proposed seems worthy of further testing, since even with the small amount of data collected it is possible to glean interesting information directly from young people which could be very useful to law-makers.

\section{References}

Aday, S., H. Farrell, M. Lynch, J. Sides, J. Kelly, and E. Zuckerman (2010). Blogs and bullets: New media in contentious politics. Washington, D.C., U.S. Institute of Peace available at http://www.usip.org/publications/blogs-and-bullets-new-media-in-contentious-politics.

Amel, V. U. (2012). Egypt's presidential elections and Twitter talk. available at http://www.jadaliyya. com/pages/index/5716/egypts-presidential-elections-and-twitter-talk.

Baxter, H. (1997). Autopoiesis and the "relative autonomy" of law. Cardozo L. Rev. 19(6), 1987.

Beebe, A., A. Blaylock, and K. D. Sweetser (2009). Job satisfaction in public relations internships. Public Relations Review 35(2), 156-158.

Bentolila, S., J. J. Dolado, W. Franz, and C. Pissarides (1994). Labour flexibility and wages: lessons from Spain. Economic policy 9(18), 55-99.

Bertola, G., F. D. Blau, and L. M. Kahn (2007). Labor market institutions and demographic employment patterns. Journal of Population Economics 20(4), 833-867.

Bird, B. (2012). Preventing employer misclassification of student interns and trainees. Cornell HR Review. available at http://www.cornellhrreview.org/ preventing-employer-misclassification-of-student-interns-and-trainees.

Blampain, R. (2014). Comparative Labour Law and Industrial Relations in Industrialized Market Economies. Kluwer law international.

Blinder, A. S. (1973). Wage discrimination: reduced form and structural estimates. Journal of Human resources $8(4), 436-455$.

Boeri, T. and P. Garibaldi (2007). Two tier reforms of employment protection: a honeymoon effect? The Economic Journal 117(521), F357-F385. 
Botero, J. C., S. Djankov, R. La Porta, F. López de Silanes, and A. Shleifer (2004). The regulation of labor. QJ Econ 119, 1339.

Buber, M. (1937). 1 and Thou,. Walter Kaufmann,(New York: Charles Scribners Sons, 1970).

Burke, D. D. and R. Carton (2013). The pedagogical, legal, and ethical implications of unpaid internships. Journal of Legal Studies Education 30(1), 99-130.

Carvalho, F. and S. Deakin (2011). System and evolution in corporate governance. Law, Economics and Evolutionary Theory, 111-130.

Cha, M., H. Haddadi, F. Benevenuto, and P. K. Gummadi (2010). Measuring user influence in Twitter: The million follower fallacy. ICWSM 10, 10-17. available at http://snap.stanford.edu/class/ cs224w-readings/cha10influence.pdf.

Coker, L. (2009). Legal implications of unpaid internships. Employee Relations Law Journal 35(3), 35.

Conover, M., J. Ratkiewicz, M. Francisco, B. Gonçalves, F. Menczer, and A. Flammini (2011). Political polarization on Twitter. In ICWSM, Volume 89. available at https://www.aaai.org/ocs/index.php/ ICWSM/ICWSM11/paper/view/2847.

Cook, S. J., R. S. Parker, and C. E. Pettijohn (2004). The perceptions of interns: A longitudinal case study. Journal of Education for Business 79(3), 179-185.

D'abate, C. P., M. A. Youndt, and K. E. Wenzel (2009). Making the most of an internship: An empirical study of internship satisfaction. Academy of Management Learning 83 Education 8(4), 527-539.

Dodds, P. S., K. D. Harris, I. M. Kloumann, C. A. Bliss, and C. M. Danforth (2011). Temporal patterns of happiness and information in a global social network: Hedonometrics and Twitter. PloS one 6(12), e26752.

Durrant, C. (2013). To benefit or not to benefit: mutually induced consideration as a test for the legality of unpaid internships. U. Pa. L. Rev. 162(1), 169.

Edwards, K. A. and A. Hertel-Fernandez (2010). Not-so-equal protection. reforming the regulation of student internships. Policy memorandum 160. available at http://epi.3cdn.net/f7d635c82f7380fff0_ 8sm6bxrzk.pdf.

Esping-Andersen, G. (1990). The three worlds of welfare capitalism. Princeton University Press.

Fairlie, R. W. (2005). An extension of the blinder-oaxaca decomposition technique to logit and probit models. Journal of economic and social measurement 30(4), 305-316.

Faust, K. and S. Wasserman (1994). Social network analysis: Methods and applications, Volume 8. Cambridge university press. 
Fazio, F. (2013). Why do so many Italians apply for a traineeship at the EU commission?,. ADAPT International Bullettin 13. available at http://www.adapt.it/englishbulletin/docs/fazio_3_9_2013. pdf.

Feldman, R. (2013). Techniques and applications for sentiment analysis. Communications of the ACM 56(4), 82-89.

Grantham, G. and M. MacKinnon (1994). Labour market evolution: the economic history of market integration, wage flexibility and the employment relation. Routledge.

Guardian, T. (2011). Reading the riots. Investigating England's summer of disorder. London School of Economics. available at http://www.theguardian.com/uk/interactive/2011/dec/14/ reading-the-riots-investigating-england-s-summer-of-disorder-full-report.

Gupta, P. B., D. J. Burns, and J. Schiferl (2010). An exploration of student satisfaction with internship experiences in marketing,. Business Education and Accreditation 2(1), 27-37.

Hadjivassiliou, K., E. Carta, T. Higgins, T. Weigel, T. Wolfgarten, K. Hensen, C. Rickard, S. Ter-Minassian, F. Pesce, M. Samek, et al. (2012). Study on a comprehensive overview on traineeship arrangements in member states: final synthesis report. available at http://ec.europa.eu/social/BlobServlet?docId= $7754 \&$ langId $=$ en.

Hall, M., G. Stiles, J. Kuzma, and K. Elliott (1995). A comparison of student and employer expectations with regard to business internships. Marketing Education Review 5(3), 41-49.

Heath, B. and D. Potter (2011). Going for broke. the state of internships in the UK, a report by internocracy, internocracy. available at http://www . bollettinoadapt.it/old/files/document/12308INTERNOCRACY_ The.pdf.

Henry, N. (1979). Are internships worthwhile? Public Administration Review, 245-247.

Hurst, J. L. and L. K. Good (2010). A 20-year evolution of internships: implications for retail interns, employers and educators. The International Review of Retail, Distribution and Consumer Research 20(1), $175-186$.

ILO (2014). Macroeconomic challenges and global labour market developments: Labour market situation of youth worsens further, in global employment trends 2014: Risk of a jobless recovery? ILO.

Jisun, A., M. Cha, P. K. Gummadi, and J. Crowcroft (2011). Media landscape in Twitter: A world of new conventions and political diversity. In ICWSM. available at http://twitter.mpi-sws.org/icwsm2011_ medialandscape.pdf.

Keiser, M., J. Joseph, and D. Reis (2013). Unpaid interns may be considered employees. Empl.Reg.L.J. 39(3), 66. 
King, G. and W. Lowe (2003). An automated information extraction tool for international conflict data with performance as good as human coders: A rare events evaluation design. International Organization 57(03), 617-642.

Lavin, H.S.and DiMichele, E. (2013). Are volunteers "employees" for purposes of Title VII? EmplRel.L.J. 39(3), 101.

Luhmann, N. (1988). Law as a social system. Nw. UL Rev. 83(1), 136.

Luhmann, N. (1991). Operational closure and structural coupling: the differentiation of the legal system. Cardozo L. Rev. 13(5), 1419.

Lyons, B. (2013). Interns are workers, too. OECD Yearbook, 33.

Maertz Jr, C. P., P. A. Stoeberl, and J. Marks (2014). Building successful internships: lessons from the research for interns, schools, and employers. Career Development International 19(1), 123-142.

Maturana, H. R. and F. J. Varela (1987). The tree of knowledge: The biological roots of human understanding. New Science Library/Shambhala Publications.

McCaffery, J. L. (1979). Perceptions of satisfaction-dissatisfaction in the internship experience. Public Administration Review 39(3), 241-244.

McKinsey (2011). Big data: The next frontier for innovation, competition and productivity. McKinsey $\mathcal{G}^{3}$ Company.

Mislove, A., S. Lehmann, Y.-Y. Ahn, J.-P. Onnela, and J. N. Rosenquist (2011). Understanding the demographics of Twitter users. ICWSM 11, 5th. available at http://www.ccs.neu.edu/home/amislove/ publications/Twitter-ICWSM.pdf.

Narayanan, V., P. M. Olk, and C. V. Fukami (2010). Determinants of internship effectiveness: An exploratory model. Academy of Management Learning \&3 Education 9(1), 61-80.

Nelson, M. H. (2010). Internships and federal law: Are interns employees? Emp. Rel. Lj. 36(2), 42.

Oaxaca, R. (1973). Male-female wage differentials in urban labor markets. International economic review, 693-709.

Oaxaca, R. L. and M. R. Ransom (1994). On discrimination and the decomposition of wage differentials. Journal of econometrics $61(1), 5-21$.

Procter, R., F. Vis, and A. Voss (2013). Reading the riots on Twitter: methodological innovation for the analysis of big data. International journal of social research methodology 16(3), 197-214. 
Rothman, M. (2007). Lessons learned: Advice to employers from interns. Journal of Education for Business 82(3), 140-144.

Shoenfelt, E. L., N. J. Stone, and J. L. Kottke (2013). Internships: An established mechanism for increasing employability. Industrial and Organizational Psychology 6(1), 24-27.

Sloan, L., J. Morgan, W. Housley, M. Williams, A. Edwards, P. Burnap, and O. Rana (2013). Knowing the tweeters: Deriving sociologically relevant demographics from Twitter. Sociological Research Online 18(3), 7.

Smayling, M. and H. Miller (2012). Job satisfaction and job performance at the internship level. Journal of Leadership, Accountability and Ethics 9(1), 27-33.

Tiraboschi, M. (2014). Labour law protections, training contracts and the problem of youth unemployment. in Blanpain R. (Ed.), Comparative Labour Law, (Op. Cit.), 489. 
Figure 1: Map of the evaluations of internships across European countries

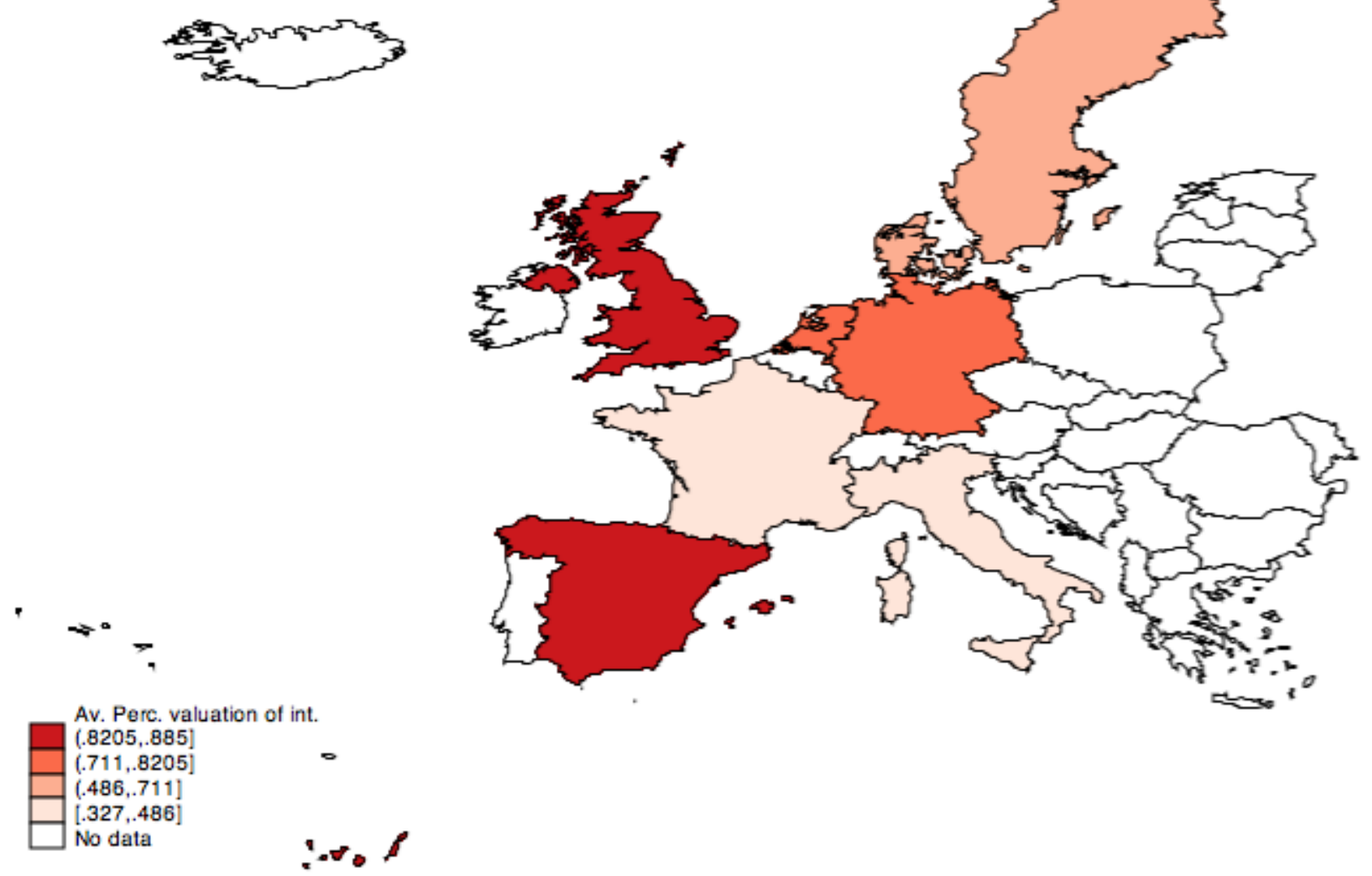

Source: Own Elaboration on on Twitter-based data analysis. 
Figure 2: Map of NEET rates in \% in 2013


Source: Own Elaboration on Eurostat. 
Figure 3: Youth unemployment rate in 2013

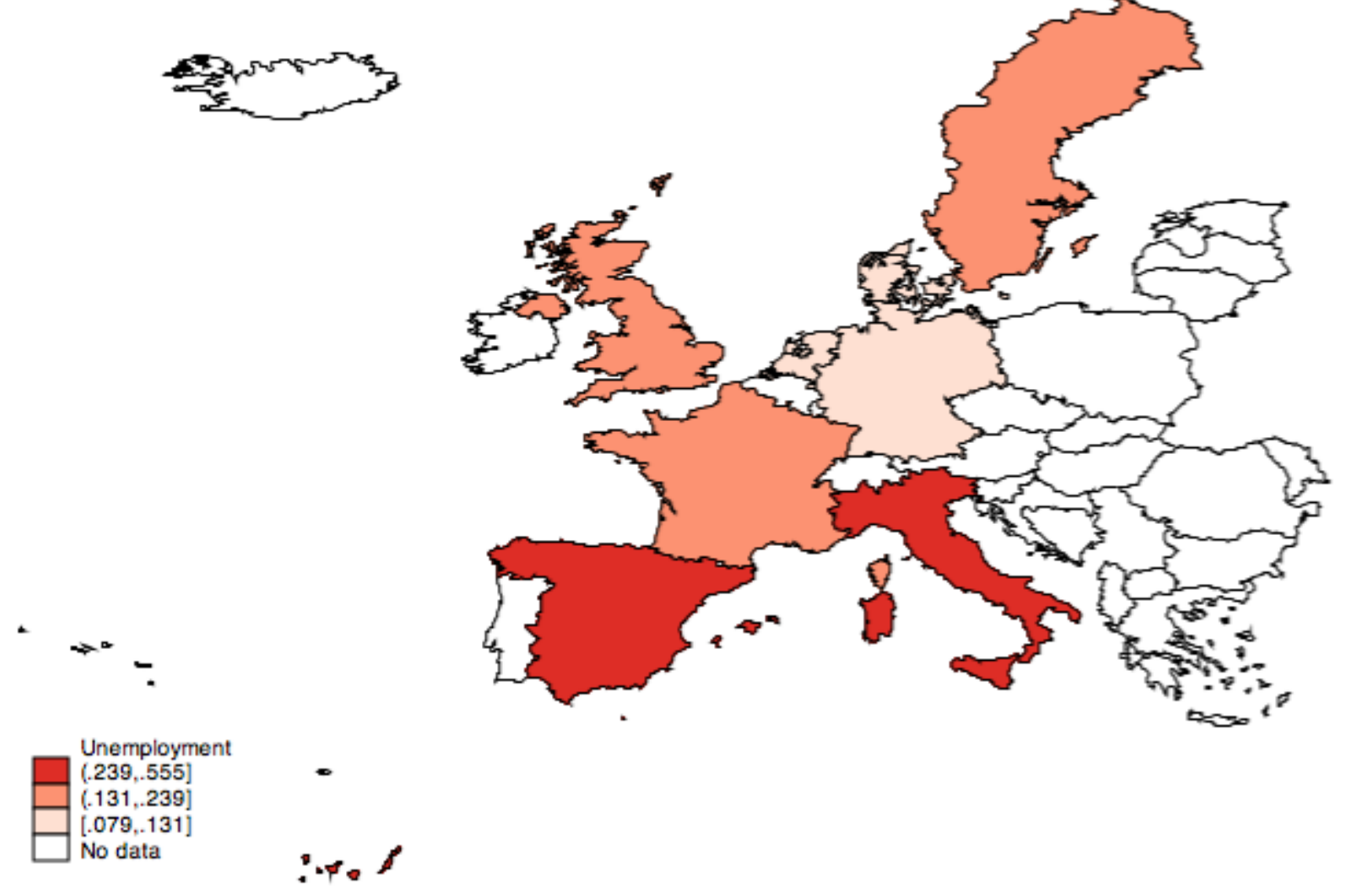

NOTE: Eurostat youth unemployment rates, 2013.

Source: Own Elaboration on Eurostat. 
Figure 4: Strictness of regulation on temporary work: fixed-term contracts and temporary work agencies (Source: OECD)

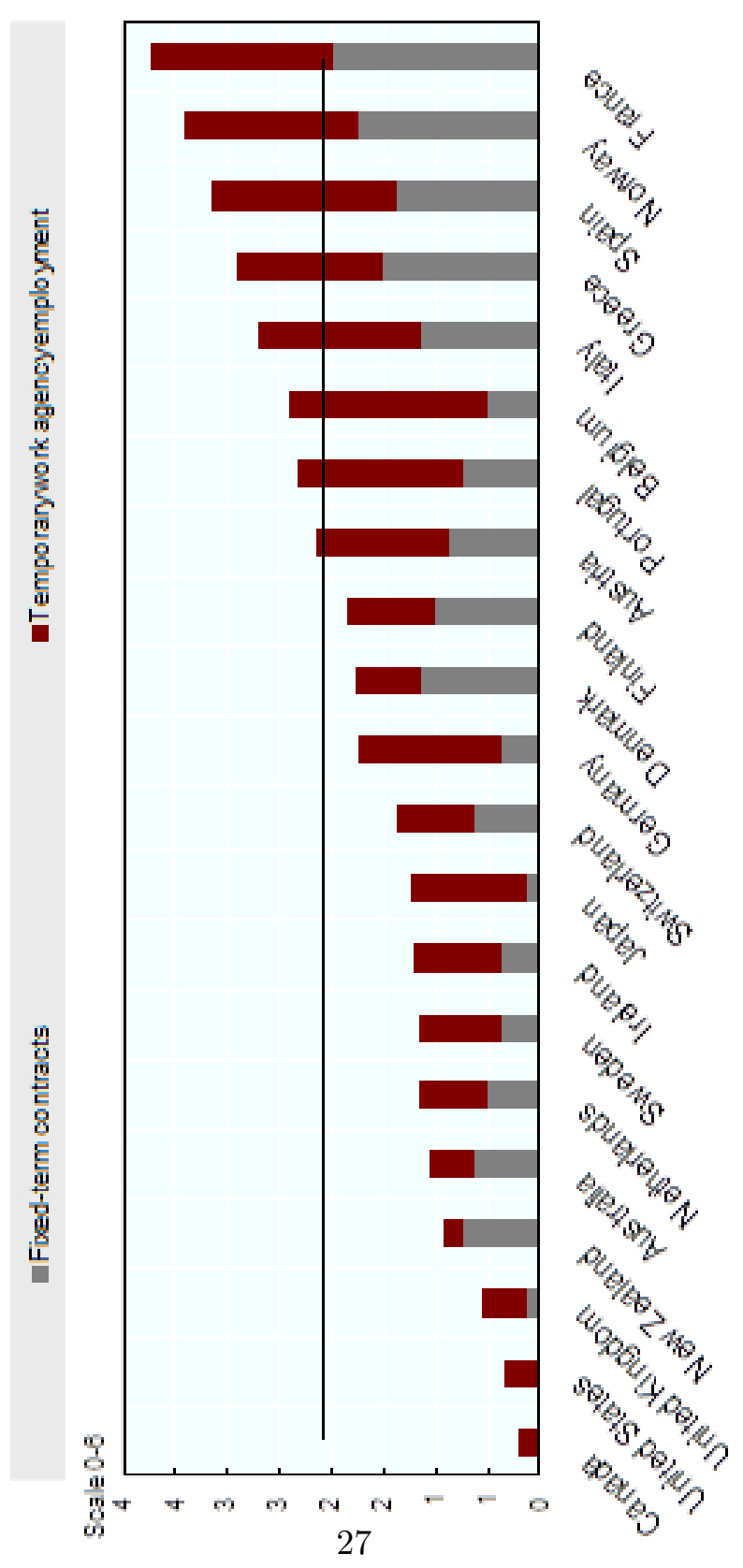


Figure 5: Regulation on temporary form of employment

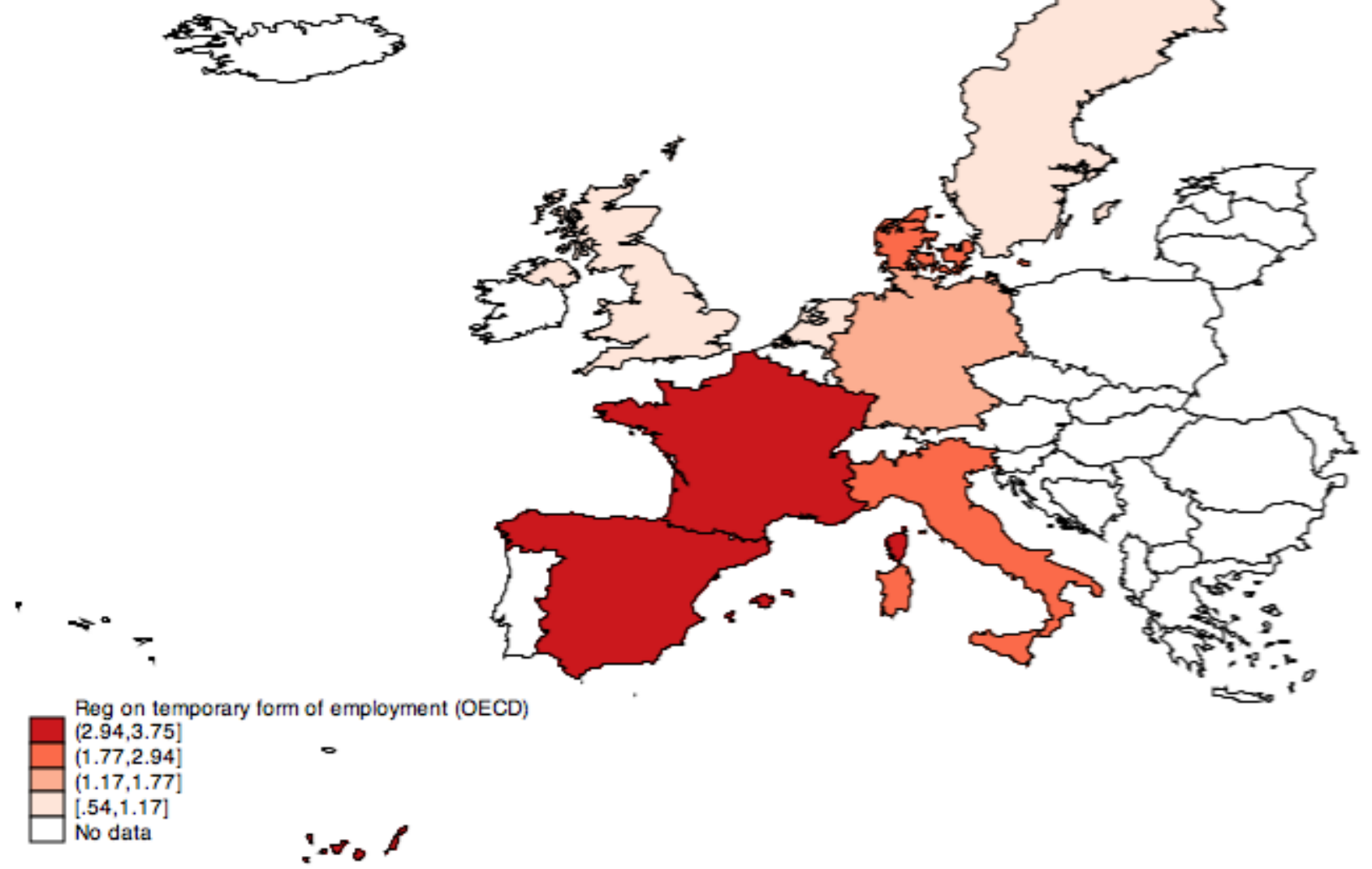

Source: Own Elaboration on OECD. 
Figure 6: Internship Regulation Index (IRI)

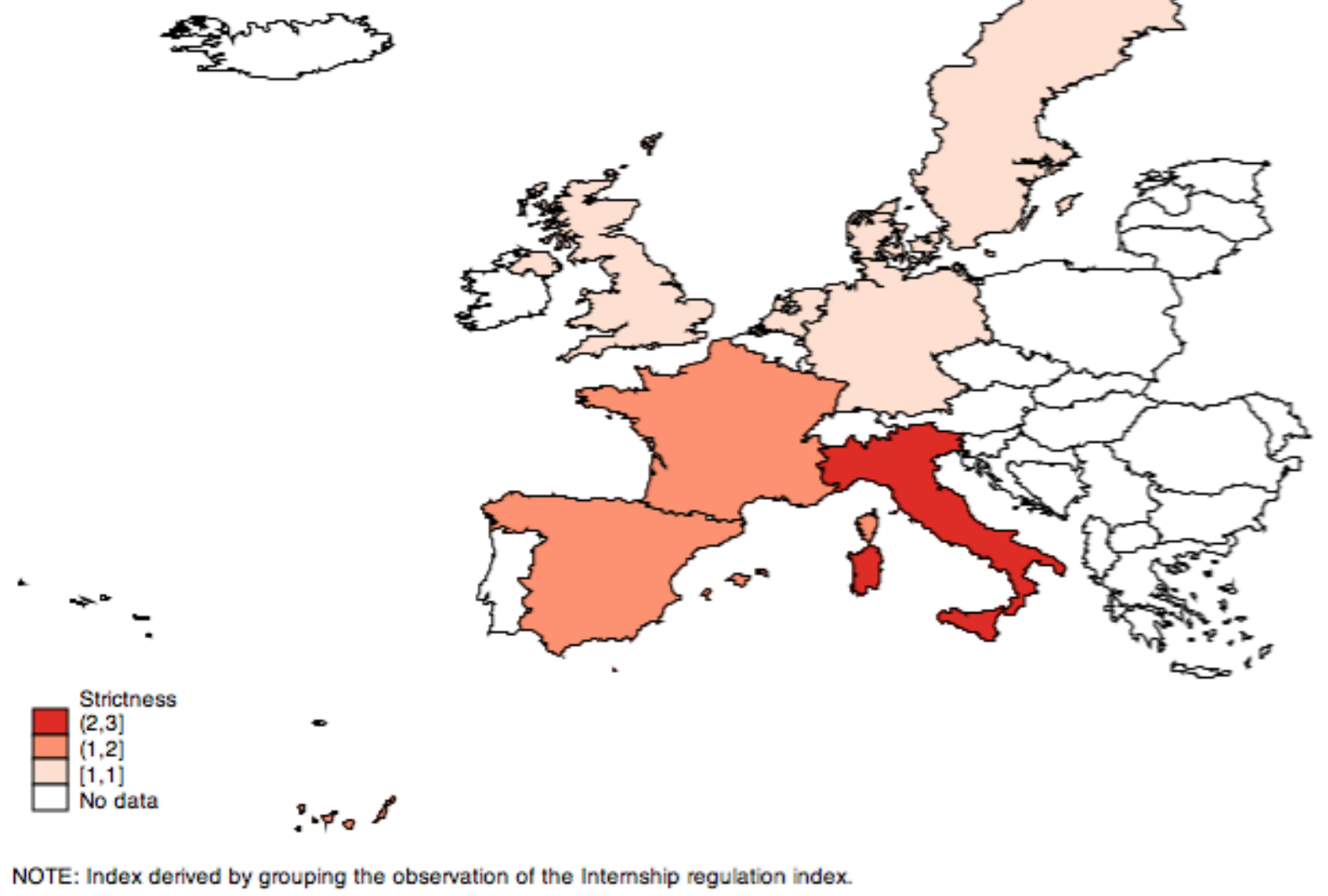

Source: Own Elaboration. 
Table 1: Summary statistics

\begin{tabular}{lcccccc}
\hline \hline & \multicolumn{2}{c}{$(1)$} & \multicolumn{2}{c}{$(2)$} & \multicolumn{2}{c}{$(3)$} \\
& \multicolumn{2}{c}{ All } & \multicolumn{2}{c}{ Negative } & \multicolumn{2}{c}{ Positive } \\
& mean & sd & mean & sd & mean & sd \\
\hline male & .297 & .457 & .378 & .486 & .220 & .415 \\
young & .049 & .217 & .054 & .226 & .051 & .221 \\
abroad & .029 & .169 & .020 & .141 & .034 & .182 \\
minwage & .453 & .498 & .425 & .496 & .472 & .500 \\
Italy & .108 & .311 & .209 & .408 & .055 & .228 \\
Holland & .099 & .298 & .067 & .251 & .120 & .326 \\
UK & .104 & .306 & .027 & .162 & .106 & .309 \\
France & .126 & .333 & .277 & .449 & .068 & .253 \\
Germany & .099 & .298 & .081 & .273 & .110 & .313 \\
Sweden & .100 & .301 & .121 & .327 & .106 & .309 \\
Norway & .011 & .108 & .006 & .082 & .013 & .116 \\
Spain & .122 & .328 & .054 & .226 & .1758 & .381 \\
Denmark & .055 & .229 & .047 & .212 & .055 & .228 \\
US & .170 & .376 & .108 & .311 & .186 & .389 \\
medicalsector & .112 & .316 & .141 & .350 & .113 & .318 \\
schoolsector & .095 & .293 & .033 & .181 & .131 & .338 \\
professionalsector & .081 & .273 & .054 & .226 & .093 & .291 \\
varioussector & .275 & .447 & .108 & .311 & .362 & .481 \\
nosector & .465 & .499 & .662 & .474 & .348 & .477 \\
\hline$N$ & 505 & & 148 & & 290 & \\
\hline \hline
\end{tabular}


Table 2: Summary Statistics (cont.)

\begin{tabular}{lcc}
\hline \hline & \multicolumn{2}{c}{ T-test } \\
\hline male & $0.158^{* * *}$ & $(3.54)$ \\
young & 0.00233 & $(0.10)$ \\
abroad & -0.0142 & $(-0.83)$ \\
minwage & -0.0467 & $(-0.93)$ \\
Italy & $0.154^{* * *}$ & $(5.07)$ \\
Holland & -0.0531 & $(-1.73)$ \\
UK & $-0.0799^{* *}$ & $(-2.94)$ \\
France & $0.208^{* * *}$ & $(6.19)$ \\
Germany & -0.0293 & $(-0.96)$ \\
Sweden & 0.0147 & $(0.46)$ \\
Norway & -0.00704 & $(-0.65)$ \\
Spain & $-0.122^{* * *}$ & $(-3.58)$ \\
Denmark & -0.00788 & $(-0.35)$ \\
US & $-0.0781^{*}$ & $(-2.12)$ \\
medicalsector & 0.0281 & $(0.84)$ \\
schoolsector & $-0.0973^{* *}$ & $(-3.27)$ \\
professionalsector & -0.0390 & $(-1.43)$ \\
\hline$N$ & 438 & \\
\hline \hline
\end{tabular}

$t$ statistics in parentheses

${ }^{*} p<0.05,{ }^{* *} p<0.01,{ }^{* * *} p<0.001$ 
Table 3: Probit Model

\begin{tabular}{|c|c|c|c|c|}
\hline & $\begin{array}{c}(1) \\
\text { Probit }\end{array}$ & $\begin{array}{l}(2) \\
\mathrm{ME}\end{array}$ & $\begin{array}{l}(3) \\
\text { Probit }\end{array}$ & $\begin{array}{l}(4) \\
\mathrm{ME}\end{array}$ \\
\hline $\begin{array}{l}\text { main } \\
\text { male }\end{array}$ & $\begin{array}{c}-0.532^{* *} \\
(0.166)\end{array}$ & $\begin{array}{c}-0.155^{* * *} \\
(0.0437)\end{array}$ & $\begin{array}{c}-0.522^{* *} \\
(0.164)\end{array}$ & $\begin{array}{c}-0.148^{* * *} \\
(0.0425)\end{array}$ \\
\hline Italy & $\begin{array}{c}-0.447^{*} \\
(0.221)\end{array}$ & $\begin{array}{c}-0.130^{*} \\
(0.0646)\end{array}$ & $\begin{array}{c}-0.560^{*} \\
(0.221)\end{array}$ & $\begin{array}{c}-0.159^{* *} \\
(0.0608)\end{array}$ \\
\hline Holland & $\begin{array}{c}0.848^{* * *} \\
(0.179)\end{array}$ & $\begin{array}{l}0.247^{* * *} \\
(0.0473)\end{array}$ & $\begin{array}{c}0.768^{* * *} \\
(0.208)\end{array}$ & $\begin{array}{l}0.218^{* * *} \\
(0.0573)\end{array}$ \\
\hline UK & $\begin{array}{c}1.226^{* * *} \\
(0.291)\end{array}$ & $\begin{array}{l}0.357^{* * *} \\
(0.0754)\end{array}$ & $\begin{array}{l}1.206^{* *} \\
(0.445)\end{array}$ & $\begin{array}{l}0.343^{* *} \\
(0.118)\end{array}$ \\
\hline France & $\begin{array}{c}-0.512^{* *} \\
(0.183)\end{array}$ & $\begin{array}{c}-0.149^{* *} \\
(0.0542)\end{array}$ & $\begin{array}{c}-0.600^{*} \\
(0.253)\end{array}$ & $\begin{array}{c}-0.170^{*} \\
(0.0709)\end{array}$ \\
\hline Germany & $\begin{array}{c}0.658^{*} \\
(0.289)\end{array}$ & $\begin{array}{c}0.192^{*} \\
(0.0823)\end{array}$ & $\begin{array}{c}0.571 \\
(0.403)\end{array}$ & $\begin{array}{c}0.162 \\
(0.109)\end{array}$ \\
\hline Sweden & $\begin{array}{c}0.431^{*} \\
(0.219)\end{array}$ & $\begin{array}{c}0.126^{*} \\
(0.0626)\end{array}$ & $\begin{array}{c}0.375 \\
(0.272)\end{array}$ & $\begin{array}{c}0.107 \\
(0.0761)\end{array}$ \\
\hline Norway & $\begin{array}{c}0.972 \\
(0.545)\end{array}$ & $\begin{array}{c}0.283 \\
(0.152)\end{array}$ & $\begin{array}{c}0.860 \\
(0.596)\end{array}$ & $\begin{array}{c}0.244 \\
(0.169)\end{array}$ \\
\hline Spain & $\begin{array}{c}1.006^{* * *} \\
(0.271)\end{array}$ & $\begin{array}{l}0.293^{* * *} \\
(0.0744)\end{array}$ & $\begin{array}{l}0.722^{*} \\
(0.282)\end{array}$ & $\begin{array}{c}0.205^{* *} \\
(0.0766)\end{array}$ \\
\hline Denmark & $\begin{array}{c}0.528 \\
(0.432)\end{array}$ & $\begin{array}{c}0.154 \\
(0.125)\end{array}$ & $\begin{array}{c}0.327 \\
(0.393)\end{array}$ & $\begin{array}{l}0.0929 \\
(0.109)\end{array}$ \\
\hline US & $\begin{array}{c}0.706^{*} \\
(0.294)\end{array}$ & $\begin{array}{c}0.206^{*} \\
(0.0801)\end{array}$ & $\begin{array}{c}0.676^{* *} \\
(0.233)\end{array}$ & $\begin{array}{c}0.192^{* *} \\
(0.0625)\end{array}$ \\
\hline Age & No & No & Yes & Yes \\
\hline Follower/Following & Yes & Yes & Yes & Yes \\
\hline Sector Cont. & No & No & Yes & Yes \\
\hline Observations & 437 & 437 & 437 & 437 \\
\hline
\end{tabular}

Standard errors in parentheses

${ }^{*} p<0.05,{ }^{* *} p<0.01,{ }^{* * *} p<0.001$ 
Table 4: Oaxaca Decomposition by gender

\begin{tabular}{lcc}
\hline & $(1)$ & $(2)$ \\
& Linear & Logit \\
\hline overall & & \\
group_1 & $0.711^{* * *}$ & $0.711^{* * *}$ \\
& $(0.0257)$ & $(0.0256)$ \\
group_2 & $0.533^{* * *}$ & $0.533^{* * *}$ \\
& $(0.0469)$ & $(0.0457)$ \\
difference & $0.177^{* * *}$ & $0.177^{* * *}$ \\
& $(0.0535)$ & $(0.0524)$ \\
endowments & -0.0000457 & -0.0000661 \\
& $(0.0196)$ & $(0.0195)$ \\
coefficients & $0.160^{* *}$ & $0.160^{* *}$ \\
& $(0.0554)$ & $(0.0546)$ \\
interaction & 0.0171 & 0.0177 \\
& $(0.0257)$ & $(0.0266)$ \\
\hline Observations & 438 & 438 \\
\hline Standard errors in parentheses & \\
${ }^{*} p<0.05,{ }^{* *} p<0.01,{ }^{* * *} p<0.001$
\end{tabular}


Table 5: Fairlie Decomposition 2002-2009

\begin{tabular}{|c|c|c|c|c|c|}
\hline & \multicolumn{5}{|c|}{ Perceived } \\
\hline & $\begin{array}{c}(1) \\
\text { Gender }\end{array}$ & $\begin{array}{c}(2) \\
\text { Gender }\end{array}$ & $\begin{array}{c}(3) \\
\text { Liberal }\end{array}$ & $\begin{array}{c}(4) \\
\text { Liberal } \\
\end{array}$ & $\begin{array}{c}(5) \\
\text { Liberal } \\
\end{array}$ \\
\hline young & $\begin{array}{c}0.000376 \\
(0.00215)\end{array}$ & $\begin{array}{c}-0.000581 \\
(0.00264)\end{array}$ & $\begin{array}{c}-0.000434 \\
(0.00231)\end{array}$ & $\begin{array}{c}-0.000713 \\
(0.00326)\end{array}$ & $\begin{array}{c}-0.0000582 \\
(0.00207)\end{array}$ \\
\hline minwage & $\begin{array}{c}0.0367 \\
(0.0303)\end{array}$ & $\begin{array}{c}0.0181 \\
(0.0107)\end{array}$ & $\begin{array}{c}0.00119 \\
(0.00811)\end{array}$ & $\begin{array}{c}0.0169^{* *} \\
(0.00561)\end{array}$ & $\begin{array}{c}0.00448 \\
(0.00712)\end{array}$ \\
\hline Country where stage is placed & $\begin{array}{l}-0.0141 \\
(0.0298)\end{array}$ & & & & \\
\hline Sector/Industry & $\begin{array}{c}0.00134 \\
(0.00563)\end{array}$ & $\begin{array}{c}-0.00291 \\
(0.00486)\end{array}$ & $\begin{array}{c}0.0381^{* *} \\
(0.0132)\end{array}$ & $\begin{array}{c}0.0190^{* *} \\
(0.00701)\end{array}$ & $\begin{array}{c}0.0454^{* * *} \\
(0.0103)\end{array}$ \\
\hline Followers & $\begin{array}{c}0.000977 \\
(0.00412)\end{array}$ & $\begin{array}{c}0.00497 \\
(0.00493)\end{array}$ & $\begin{array}{c}0.0118 \\
(0.0101)\end{array}$ & $\begin{array}{c}0.0154 \\
(0.0107)\end{array}$ & $\begin{array}{c}0.0186 \\
(0.0124)\end{array}$ \\
\hline Following & $\begin{array}{l}-0.00869 \\
(0.00570)\end{array}$ & $\begin{array}{l}-0.00975 \\
(0.00522)\end{array}$ & $\begin{array}{c}-0.0417^{* *} \\
(0.0142)\end{array}$ & $\begin{array}{c}-0.0363^{* *} \\
(0.0139)\end{array}$ & $\begin{array}{c}-0.0466^{* *} \\
(0.0157)\end{array}$ \\
\hline Legal & & $\begin{array}{c}0.0192^{* *} \\
(0.00738)\end{array}$ & & & \\
\hline male & & & $\begin{array}{c}-0.00393 \\
(0.00321)\end{array}$ & $\begin{array}{l}-0.00459 \\
(0.00379)\end{array}$ & $\begin{array}{l}-0.00499 \\
(0.00393)\end{array}$ \\
\hline Temp. Prot. & & & & $\begin{array}{c}-0.245^{* * *} \\
(0.0343)\end{array}$ & \\
\hline Internship strictness & & & & & $\begin{array}{c}-0.125^{* * *} \\
(0.0214)\end{array}$ \\
\hline Observations & 437 & 437 & 437 & 437 & 437 \\
\hline Perc (Women/Non-Lib) & 0.711 & 0.711 & 0.616 & 0.616 & 0.616 \\
\hline Perc (Men/Lib) & 0.538 & 0.538 & 0.817 & 0.817 & 0.817 \\
\hline Difference & 0.173 & 0.173 & -0.202 & -0.202 & -0.202 \\
\hline Tot Expl. Difference & 0.0157 & 0.0288 & 0.00509 & -0.236 & -0.110 \\
\hline
\end{tabular}

Standard errors in parentheses

${ }^{*} p<0.05,{ }^{* *} p<0.01,{ }^{* * *} p<0.001$ 
Table 6: Probit Model

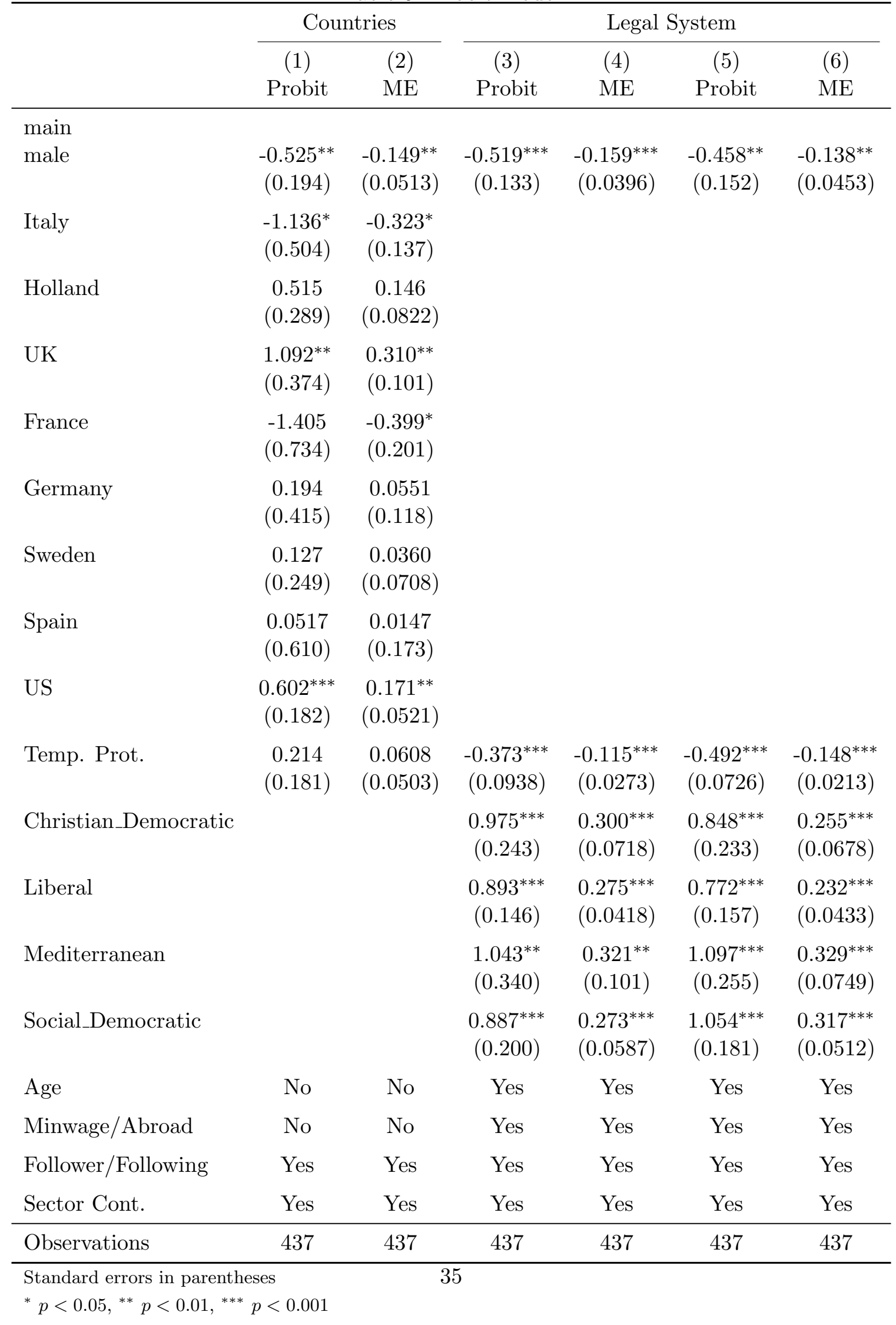


Table 7: Probit Model

\begin{tabular}{|c|c|c|c|c|c|c|}
\hline & \multicolumn{2}{|c|}{ Countries } & \multicolumn{4}{|c|}{ Legal System } \\
\hline & (1) & (2) & (3) & (4) & $(5)$ & (6) \\
\hline & Probit & $\mathrm{ME}$ & Probit & $\mathrm{ME}$ & Probit & $\mathrm{ME}$ \\
\hline $\begin{array}{l}\text { main } \\
\text { male }\end{array}$ & $\begin{array}{c}-0.525^{* * *} \\
(0.144)\end{array}$ & $\begin{array}{c}-0.149^{* * *} \\
(0.0400)\end{array}$ & $\begin{array}{c}-0.517^{* * *} \\
(0.155)\end{array}$ & $\begin{array}{c}-0.150^{* * *} \\
(0.0433)\end{array}$ & $\begin{array}{c}-0.490^{* * *} \\
(0.139)\end{array}$ & $\begin{array}{c}-0.142^{* * *} \\
(0.0387)\end{array}$ \\
\hline Italy & $\begin{array}{l}-1.686^{*} \\
(0.721)\end{array}$ & $\begin{array}{l}-0.479^{*} \\
(0.204)\end{array}$ & & & & \\
\hline Holland & $\begin{array}{c}0.389 \\
(0.333)\end{array}$ & $\begin{array}{c}0.111 \\
(0.0943)\end{array}$ & & & & \\
\hline UK & $\begin{array}{l}0.831^{*} \\
(0.393)\end{array}$ & $\begin{array}{l}0.236^{*} \\
(0.108)\end{array}$ & & & & \\
\hline France & $\begin{array}{c}-1.356^{* *} \\
(0.512)\end{array}$ & $\begin{array}{c}-0.385^{* *} \\
(0.146)\end{array}$ & & & & \\
\hline Germany & $\begin{array}{c}0.192 \\
(0.332)\end{array}$ & $\begin{array}{c}0.0545 \\
(0.0939)\end{array}$ & & & & \\
\hline Sweden & $\begin{array}{c}0.000662 \\
(0.292)\end{array}$ & $\begin{array}{c}0.000188 \\
(0.0828)\end{array}$ & & & & \\
\hline Spain & $\begin{array}{c}-0.0233 \\
(0.580)\end{array}$ & $\begin{array}{c}-0.00663 \\
(0.165)\end{array}$ & & & & \\
\hline US & $\begin{array}{c}0.296 \\
(0.324)\end{array}$ & $\begin{array}{c}0.0841 \\
(0.0914)\end{array}$ & & & & \\
\hline Internship strictness & $\begin{array}{c}0.376 \\
(0.260)\end{array}$ & $\begin{array}{c}0.107 \\
(0.0743)\end{array}$ & $\begin{array}{c}-1.113^{* * *} \\
(0.190)\end{array}$ & $\begin{array}{c}-0.323^{* * *} \\
(0.0478)\end{array}$ & $\begin{array}{c}-1.104^{* * *} \\
(0.157)\end{array}$ & $\begin{array}{c}-0.320^{* * *} \\
(0.0383)\end{array}$ \\
\hline Christian_Democratic & & & $\begin{array}{c}1.708^{* * *} \\
(0.349)\end{array}$ & $\begin{array}{l}0.496^{* * *} \\
(0.0914)\end{array}$ & $\begin{array}{c}1.546^{* * *} \\
(0.321)\end{array}$ & $\begin{array}{c}0.448^{* * *} \\
(0.0889)\end{array}$ \\
\hline Liberal & & & $\begin{array}{c}1.921^{* * *} \\
(0.269)\end{array}$ & $\begin{array}{l}0.558^{* * *} \\
(0.0643)\end{array}$ & $\begin{array}{c}1.851^{* * *} \\
(0.269)\end{array}$ & $\begin{array}{c}0.537^{* * *} \\
(0.0691)\end{array}$ \\
\hline Mediterranean & & & $\begin{array}{c}2.835^{* * *} \\
(0.556)\end{array}$ & $\begin{array}{c}0.824^{* * *} \\
(0.146)\end{array}$ & $\begin{array}{c}2.716^{* * *} \\
(0.476)\end{array}$ & $\begin{array}{c}0.787^{* * *} \\
(0.128)\end{array}$ \\
\hline Social_Democratic & & & $\begin{array}{c}1.572^{* * *} \\
(0.253)\end{array}$ & $\begin{array}{c}0.457^{* * *} \\
(0.0621)\end{array}$ & $\begin{array}{c}1.555^{* * *} \\
(0.233)\end{array}$ & $\begin{array}{l}0.451^{* * *} \\
(0.0579)\end{array}$ \\
\hline Age & No & No & Yes & Yes & Yes & Yes \\
\hline Minwage/Abroad & No & No & Yes & Yes & Yes & Yes \\
\hline Follower/Following & Yes & Yes & Yes & Yes & Yes & Yes \\
\hline Sector Cont. & Yes & Yes & Yes & Yes & Yes & Yes \\
\hline Observations & 437 & 437 & 437 & 437 & 437 & 437 \\
\hline
\end{tabular}


Table 8: Internship Regulation Indexs

\begin{tabular}{|l|l|l|l|l|l|l|l|}
\hline & $\begin{array}{l}\text { Mand. } \\
\text { pay }\end{array}$ & $\begin{array}{l}\text { Is there a max } \\
\text { duration } \\
\text { of 6 months? } \\
\text { or lower? }\end{array}$ & $\begin{array}{l}\text { Age } \\
\text { limits }\end{array}$ & $\begin{array}{l}\text { Specific } \\
\text { legislation }\end{array}$ & $\begin{array}{l}\text { Only in } \\
\text { education }\end{array}$ & $\begin{array}{l}\text { Mand. } \\
\text { written } \\
\text { agreement }\end{array}$ & Total \\
& $\begin{array}{l}\text { Yes 1 } \\
\text { No 0 }\end{array}$ & $\begin{array}{l}\text { Yes 1 } \\
\text { No 0 }\end{array}$ & $\begin{array}{l}\text { Yes 1 } \\
\text { No 0 }\end{array}$ & $\begin{array}{l}\text { Yes 1 } \\
\text { No 0 }\end{array}$ & $\begin{array}{l}\text { Yes 1 } \\
\text { No 0 }\end{array}$ & $\begin{array}{l}\text { Yes 1 } \\
\text { No 0 }\end{array}$ & \\
\hline UK & No & No & No & No & No & No & 0 \\
\hline US & No & No & No & No & No & No & 0 \\
\hline Netherlands & No & No & No & No & No & Yes & 1 \\
\hline Sweden & No & No & Yes & No & No & Yes & 1 \\
\hline Denmark & No & No & Yes & No & No & Yes & 2 \\
\hline Germany & Yes & No & No & No & No & Yes & 2 \\
\hline Norway & Yes & No & Yes & No & No & Yes & 3 \\
\hline Spain & No & No & Yes & No & No & Yes & 3 \\
\hline France & Yes & No & No & Yes & Yes & Yes & 4 \\
\hline Italy & Yes & Yes & Yes & Yes & No & Yes & 5 \\
\hline
\end{tabular}




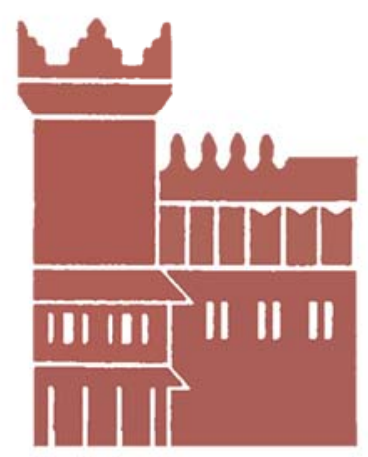

Alma Mater Studiorum - Università di Bologna DEPARTMENT OF ECONOMICS

Strada Maggiore 45

40125 Bologna - Italy

Tel. +39051 2092604

Fax +390512092664

http://www.dse.unibo.it 